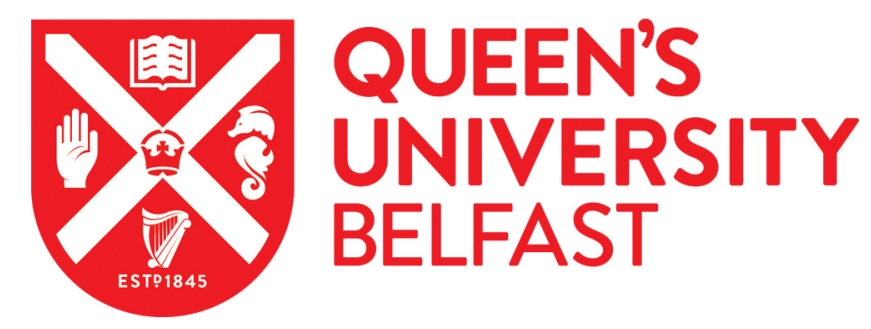

\title{
Ultrasensitive Embedded Sensor for Composite Joints Based on a Highly Aligned Carbon Nanotube Web
}

Falzon, B., Hawkins, S., \& Kumar, S. (2019). Ultrasensitive Embedded Sensor for Composite Joints Based on a Highly Aligned Carbon Nanotube Web. Carbon, 149, 380-389. https://doi.org/10.1016/j.carbon.2019.04.044

\section{Published in:}

Carbon

\section{Document Version:}

Peer reviewed version

Queen's University Belfast - Research Portal:

Link to publication record in Queen's University Belfast Research Portal

\section{Publisher rights}

Copyright 2019 Elsevier.

This manuscript is distributed under a Creative Commons Attribution-NonCommercial-NoDerivs License

(https://creativecommons.org/licenses/by-nc-nd/4.0/), which permits distribution and reproduction for non-commercial purposes, provided the author and source are cited.

\section{General rights}

Copyright for the publications made accessible via the Queen's University Belfast Research Portal is retained by the author(s) and / or other copyright owners and it is a condition of accessing these publications that users recognise and abide by the legal requirements associated with these rights.

Take down policy

The Research Portal is Queen's institutional repository that provides access to Queen's research output. Every effort has been made to ensure that content in the Research Portal does not infringe any person's rights, or applicable UK laws. If you discover content in the Research Portal that you believe breaches copyright or violates any law, please contact openaccess@qub.ac.uk. 


\section{Accepted Manuscript}

Ultrasensitive Embedded Sensor for Composite Joints Based on a Highly Aligned

Carbon Nanotube Web

Sandeep Kumar, Brian G. Falzon, Stephen C. Hawkins

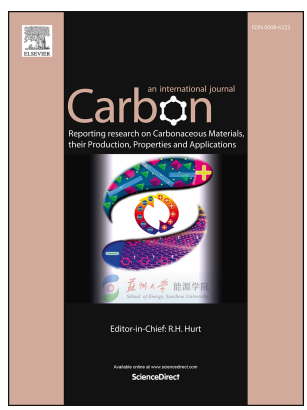

PII: S0008-6223(19)30378-1

DOI: $\quad$ https://doi.org/10.1016/j.carbon.2019.04.044

Reference: CARBON 14128

To appear in: Carbon

Received Date: 6 January 2019

Revised Date: 11 April 2019

Accepted Date: 12 April 2019

Please cite this article as: S. Kumar, B.G. Falzon, S.C. Hawkins, Ultrasensitive Embedded Sensor for Composite Joints Based on a Highly Aligned Carbon Nanotube Web, Carbon (2019), doi: https:// doi.org/10.1016/j.carbon.2019.04.044.

This is a PDF file of an unedited manuscript that has been accepted for publication. As a service to our customers we are providing this early version of the manuscript. The manuscript will undergo copyediting, typesetting, and review of the resulting proof before it is published in its final form. Please note that during the production process errors may be discovered which could affect the content, and all legal disclaimers that apply to the journal pertain. 


\title{
Ultrasensitive Embedded Sensor for Composite Joints Based on a Highly Aligned
}

\section{Carbon Nanotube Web}

\author{
Sandeep Kumar ${ }^{\text {a }}$, Brian G. Falzon ${ }^{a^{*}}$ and Stephen C. Hawkins ${ }^{\text {a,b }}$ \\ ${ }^{a}$ Advanced Composites Research Group, School of Mechanical and Aerospace Engineering, \\ Queen's University Belfast, Belfast BT9 5AH, UK \\ ${ }^{\mathrm{b}}$ Department of Materials Science and Engineering, Monash University, Clayton, Victoria
} 3800, Australia

Corresponding author, Tel.: +44 (0)28 90975640 ;

b.falzon@qub.ac.uk

Abstract: Herein, we present a novel approach for damage sensing in adhesively bonded joints using a carbon nanotube single layer web (CNT-SLW) which marks a significant departure from the approach of dispersing CNTs within epoxy resins. In this work, a very thin, highly aligned CNT-SLW (densified thickness $\sim 50 \mathrm{~nm}$ ) with aerial density of 2.0 $\mu \mathrm{g} / \mathrm{cm}^{2}$ was horizontally drawn from a vertically aligned CNT forest, positioned over an adhesive film, which was, in turn, placed between two non-conductive composite adherents. This was followed by the application of heat and pressure to cure the adhesive. These joints were subjected to quasi-static and cyclic loading to investigate the damage sensing performance of a CNT-SLW. The CNT-SLW sensor, placed parallel to the load direction, exhibits remarkably high cyclic stability as well as exceptionally high sensitivity to damage initiation and accumulation. The resistance increase $\left(\Delta R / R_{0} \% \sim 1633 \%\right)$ is significantly higher than that of adhesive sensors with dispersed CNTs/graphene, reported in the literature. Morphological studies help to explain the sensing mechanism through interactions of the CNT-SLW with the evolution of micro-cracks. These results demonstrate the potential of 
macroscopic architectures of CNTs with controlled orientation for the development of high performance structural health monitoring (SHM) systems for specific damage detection.

\section{Introduction}

Current wide-bodied passenger aircraft structures are increasingly being manufactured from carbon fibre reinforced polymer (CFRP) composites owing to the material's specific strength and stiffness, corrosion and fatigue resistance. The drive towards greater manufacturing efficiency has also led to the development of larger and more integrated structures and a preference for adhesive bonding over mechanical fasteners [1].

Structural joints are examined periodically as part of an aircraft's maintenance schedule, using a variety of inspection methods. The move towards condition-based maintenance (CDM), as opposed to scheduled 'checks', can potentially reduce the overall operational costs. However, reliable and robust health monitoring methods have yet to be developed for ensuring the structural integrity of adhesively-bonded joints which may not be easily accessed and, even if possible, disassembly of the joints results in damage to the adherent and surrounding structure [2]. In situ monitoring of structural health, in adhesive bonded joints, is a critical area of research and development [3]. Recently, Fibre Bragg Gratings (FBG) embedded in bonded structures have shown promise in sensing damage through the detection of ultrasonic Lamb waves. However, interpretation of the data is complex and needs special data acquisition equipment [4-6].

Over the past two decades, carbon nanotubes (CNTs) have attracted considerable attention due to their unique mechanical and electro-thermal properties and shown promise for damage sensing in composites [7]. Much of the initial work has used randomly oriented percolating networks of nanotubes in a polymer matrix to create conductive nanocomposites [8-16]. Interestingly, the nanoscale-percolating network of CNTs enables the monitoring of crack 
initiation and propagation at a scale at which most non-destructive techniques are ineffective $[8]$.

Several research groups have demonstrated damage initiation and propagation in lap-bonded joints using randomly dispersed CNTs where the electrical connections were made via the joint elements (metal or composite adherends) to measure the resistance of the CNT-adhesive layer under static or fatigue loading [2,17-19]. For example, Mactabi et al. studied CNTepoxy bonded aluminium joints subjected to fatigue loading [2]. Kwon et al. used CNTepoxy paste to fill cracks in, and coat, carbon fiber/polypropylene (CF/PP) composites for the evaluation of crack extension and fracture [17]. Kang et al. employed CNT-epoxy adhesive as a sensor for fatigue life and crack detection in aluminium joints, noting that the adhesive itself gave a 19-fold increased fatigue life despite a $36 \%$ reduction in bond strength [18]. Lim et al. experimentally evaluated the sensing capability of CNT-epoxy and distinguished different types of damage mechanisms in composite-to-metal joints [19]. Most recently, CNT doping of commercially available adhesive films/polymeric films also attracted great interest for sensing applications [20-24]. Sanchez-Romate et al. explored the sensing capability of bonded joints made with carbon nanotube doped adhesive films [21].

There exists several constraints with these techniques. Achieving adequate nanoscale level dispersion of CNTs in solvents for doping or forming randomly percolated of CNTs in an epoxy/polymer matrix remains a challenge due to strong aggregation tendencies of CNTs (due to high surface area and intrinsic van der Waals interactions) and increase in viscosity imposes significant issues in processing. Of critical importance however, and as demonstrated by the work of Kang et al., the sensor itself must not alter the behaviour of the joint [18].

We now report the novel application of a highly aligned carbon nanotube single layer web (CNT-SLW), of negligible weight, to monitor the state of damage in adhesively-bonded 
single-lap composite joints. Directly drawn CNT webs exhibit a uniform highly-aligned network, eliminating the agglomeration challenges encountered when dispersing in bulk resin. As the CNTs are highly aligned in the direction of draw, the resistivity perpendicular to the draw direction is approximately 20 times higher than that parallel to the draw direction [25]. Joints were subjected to quasi-static and cyclic loading tests to investigate the influence of CNT-SLW orientation on the damage sensing and joint performance.

\section{Experimental procedures}

\subsection{Materials}

Plain weave glass fibre epoxy 'prepreg' was used to manufacture the adherends. $2.0 \mathrm{~mm}$ panels were prepared by laying up eight plies of prepeg (Gurit SE84 LV, each ply thickness $0.32 \mathrm{~mm}$ ) followed by vacuum bagging and then curing using a programmable Genlab ${ }^{\mathrm{TM}}$ general purpose oven. The curing was performed at $120^{\circ} \mathrm{C}$ for one hour under vacuum. Cytec FM300 high-temperature epoxy film adhesive (thickness $\sim 0.26 \mathrm{~mm}$ ), with a polyester carrier, was used in this work. Copper foil (Alfa Aesar, $0.025 \mathrm{~mm}$ thick, annealed, uncoated, 99.8\%) was used for the electrical buses. A highly aligned CNT-SLW with an as-formed (undensified) thickness $\sim 2.5 \mu \mathrm{m}$ (densified thickness $\sim 50 \mathrm{~nm}$ ), with aerial density of 2.0 $\mu \mathrm{g} / \mathrm{cm}^{2}$ was used in this study. The fine continuous CNT webs, with controlled alignment, were horizontally drawn from a few micrograms of vertically aligned CNTs forests (each individual CNT diameter $\sim 10 \mathrm{~nm}$ and length $\sim 170$ micron) grown in-house on silicon substrates using a CVD (chemical vapour deposition) method [26]. Fig.1 confirms that the CNT web maintains a high degree of alignment. Each single CNT 'fibre' in the web is made of up countless short CNTs interconnected through strong van der Waals forces. 


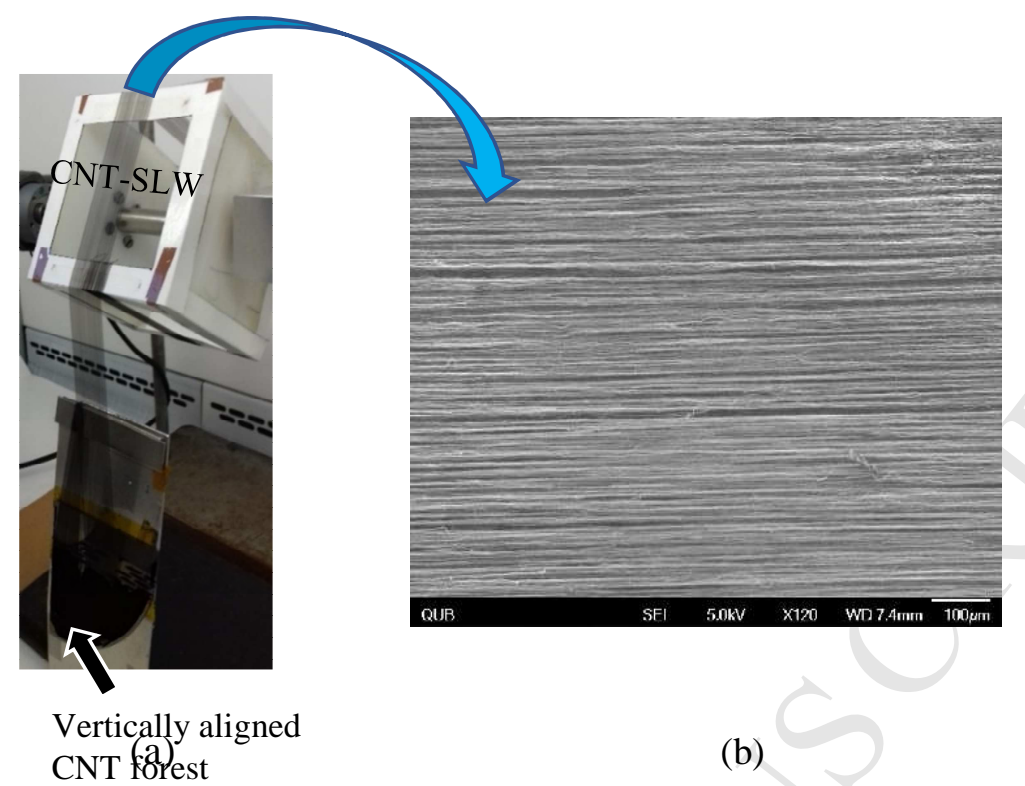

Fig.1: (a) CNT-SLW (as-formed thickness $\sim 0.6 \mu \mathrm{m}$ and aerial density of $2.0 \mu \mathrm{g} / \mathrm{cm}^{2}$ ) horizontally drawn from vertically aligned CNT forest (b) Low magnification FESEM image of surface morphology of the horizontally aligned CNT-SLW.

\subsection{CNT-SLW embedded joint preparation}

To fabricate the bonded joints with embedded CNT-SLW, the glass fibre laminate panels were cut into rectangular strips ('adherends') of size $100 \mathrm{~mm}$ x $25 \mathrm{~mm}$ x $2 \mathrm{~mm}$ according to ASTM D5868. A square $(25 \mathrm{~mm})$ piece of film adhesive was adhered coincident with the end of one adherend and the backing film removed. A CNT-SLW of width and length $>25 \mathrm{~mm}$ was placed over the adhesive film with draw direction either parallel $(/ /)$ or perpendicular $(\perp)$ to the load direction (Fig.2). A second adherend was placed on the CNT-SLW/adhesive with its end coincident with the adhesive film to form the lap-shear specimens (Fig. 3). The completed assembly was manually tightened using G-type clamps and cured at $177^{\circ} \mathrm{C}$ (Genlab ${ }^{\mathrm{TM}}$ general-purpose oven) for 1 hour. The CNT web was connected to a power source through the copper electrodes as shown in Fig. 3. Note that for the web orientation perpendicular to the load direction, the electrodes also rotated with the web and to make 


\section{ACCEPTED MANUSCRIPT}

electrical connections, the overhung edge of the CNT web folded onto the edge of the specimen. Initial investigations where the copper bus locations remained unchanged from those used for the web parallel to the load direction exhibited high resistance and failed to adequately capture the evolution of damage. Silver paste was used to ensure ohmic contact between buses and web.

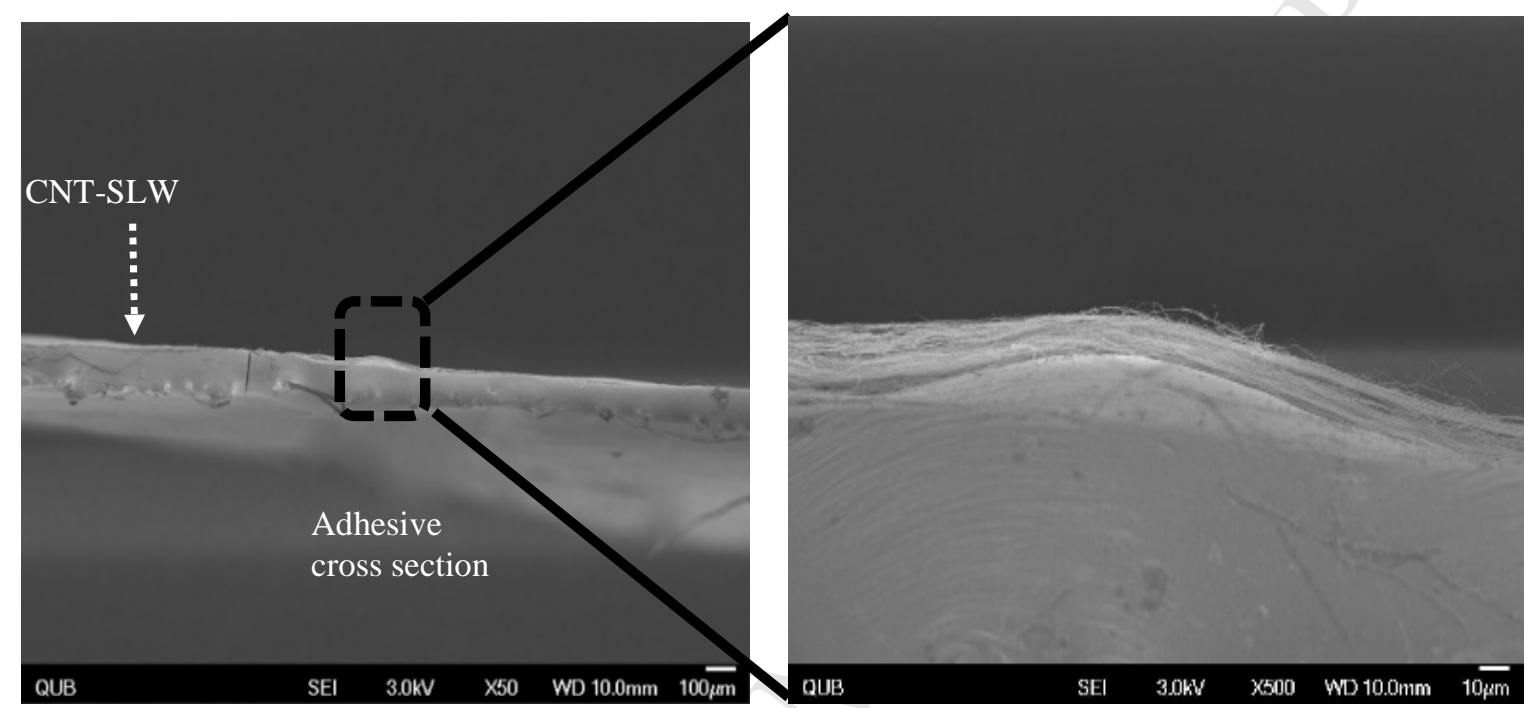

(a)

(b)

Fig.2: (a) Side view section of CNT-SLW placed over adhesive (b) magnified image.

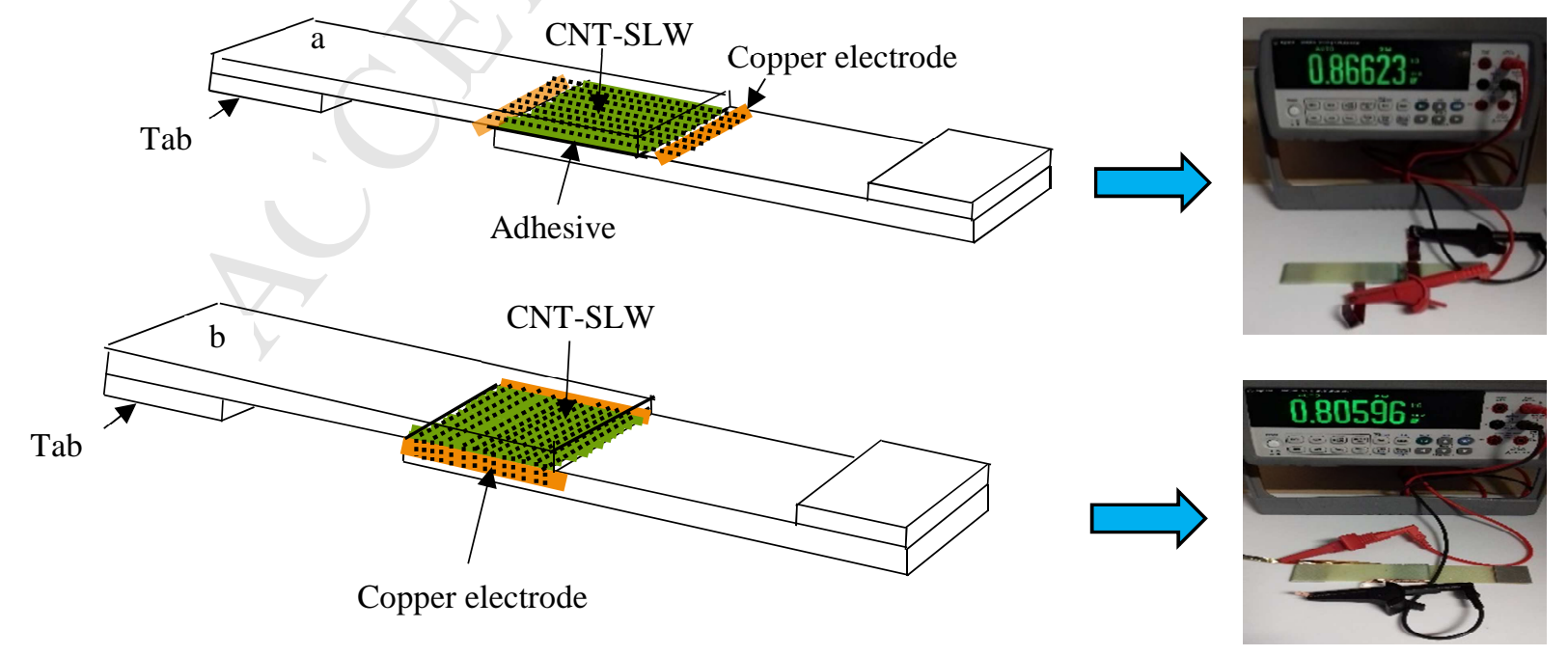


Fig.3: Lap joint embedded with CNT-SLW sensor (a) parallel and (b) perpendicular to the loading direction and corresponding digital images of sensors under zero load condition.

\section{Characterization:}

The as-grown spinnable vertically aligned mutiwalled carbon tubes (VA-MWCNTs) and CNT-SLW were characterised by Field emission Scanning electron microscopy (FESEM) (JEOL: JSM 6500 F), Transmission electron microscope (TEM) and X-ray diffractometer (XRD) (Model: $\mathrm{X}^{\prime}$ pert Pro). Thermogravimetric analysis (TGA) was performed with a Metler toldeo TGASDTA851 ${ }^{\mathrm{e}}$ at a ramp rate of $10{ }^{\circ} \mathrm{C} / \mathrm{min}$ from 50 to $700{ }^{\circ} \mathrm{C}$. The Raman scattering spectra of CNT-SLW performed using a $632 \mathrm{~nm} \mathrm{~N} \mathrm{~N}_{2}-\mathrm{H}_{2}$ laser excitation Raman spectroscopy (LabRAM 300, Horiba, UK with a $632 \mathrm{~nm}$ source). The operating current and voltage of the laser box is $7 \mathrm{~mA}$ and $3.7 \mathrm{kV}$, respectively. For all samples, a $1 \%$ filter of the output power was chosen, to avoid the surface damages of the materials. Measurements at three different positions were conducted for each sample to validate the reproducibility. A Zwick/Roell tensile testing machine (Model: Z100) with a $100 \mathrm{kN}$ load cell was used for the quasi-static tensile testing of the joints. The joints were loaded under tension at a crosshead displacement rate of $1 \mathrm{~mm} / \mathrm{min}$. The nominal free length of the joints between the grip wedges was $125 \mathrm{~mm}$. The maximum peak load, from the load vs displacement curves, was used to obtain the shear strength. A digital multimeter (Agilent 34450A) was used to measure the conductivity of CNT-SLW and to record the resistance change across the joints (Fig. 4).

To quantify the CNT-SLW sensor response to deformation, $\Delta \mathrm{R} / \mathrm{R}_{\mathrm{o}}$ was plotted against displacement, $\left(\Delta R=R-R_{0}\right)$ where $R_{o}$ is the resistance at zero displacement and $R$ is the resistance under load. For cyclic loading, ten loading cycles were conducted for each type of sample with two displacement (d) ratios (minimum displacement / maximum displacement) before and after damage initiation. For example $d$ (before damage initiation) $=0.2$, where the 
maximum displacement was $25 \%$ of the displacement at failure of the static joint, and (ii) d (after damage initiation $)=0.09,0.06$ and 0.05, where the maximum displacement was 55, 75 and $80 \%$ of the displacement at failure of the static joint. To gain further insight into the CNT-SLW sensing mechanism, microstructural analysis of the fractured joints was performed using FESEM

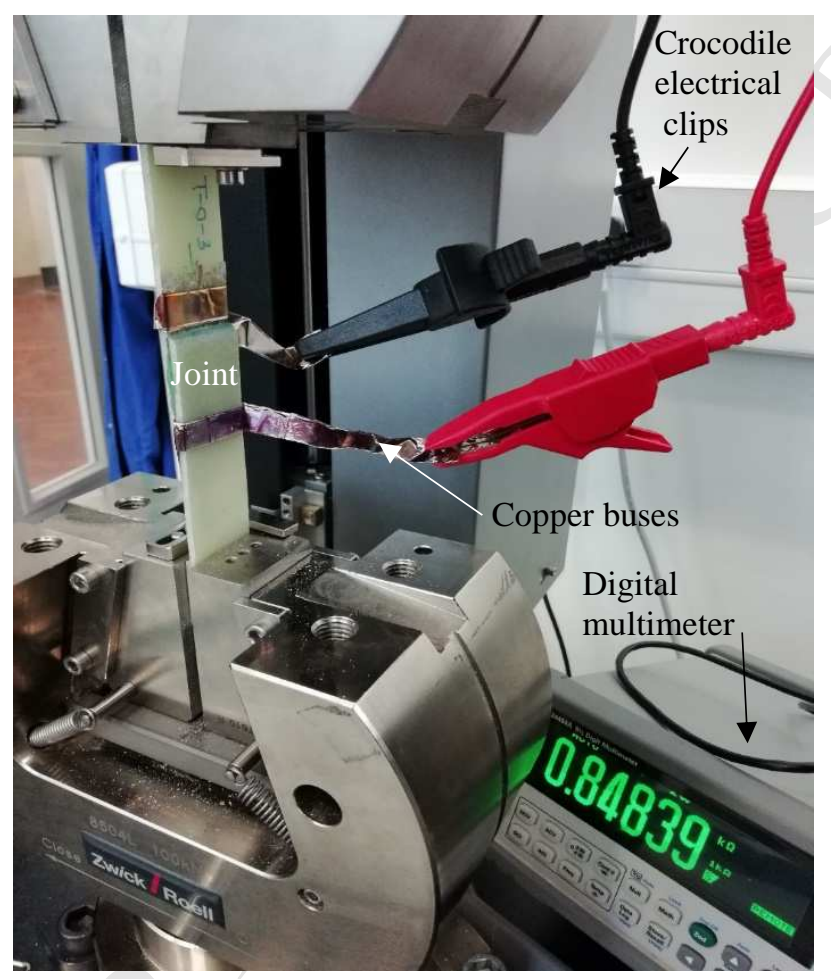

Fig.4: Experimental set-up for damage sensing in joints through real time resistance measurement.

\section{Results and discussion}

The FESEM image (Fig. 5a) clearly shows that the CNT forest arrays synthesized by chemical vapour deposition are closely packed and uniformly distributed. The CNTs are highly aligned in the array, as observed at a higher magnification (Fig. 5b). Fig. 5c presents a capturing of continuous CNT-SLW web drawing and it can be observed that CNTs re-orient from the vertical direction in the CNT arrays to horizontal direction in the newly formed 


\section{ACCEPTED MANUSCRIPT}

CNT-SLW. The as prepared, CNT-SLW exhibits a high degree of alignment (Fig. 5d) and spacing between the individual CNT fibres or fibre bundles. The HRTEM image (Fig. 6a) of CNTs confirms that the CNTs have multiple walls $(7 \pm 3)$ with inner and outer diameters of $4 \pm 1 \mathrm{~nm}$ and $10 \pm 3 \mathrm{~nm}$, respectively. TEM image shows the presence of very little amorphous carbon and confirms that the CNTs are free from catalysts particles. TGA analysis (Fig.6b) shows the onset of degradation at $505^{\circ} \mathrm{C}$ and indicates absence of any catalyst remnants from no residual mass left and support the TEM observations [26]. The CNTs with such a higher purity are highly desirable for electrical applications.
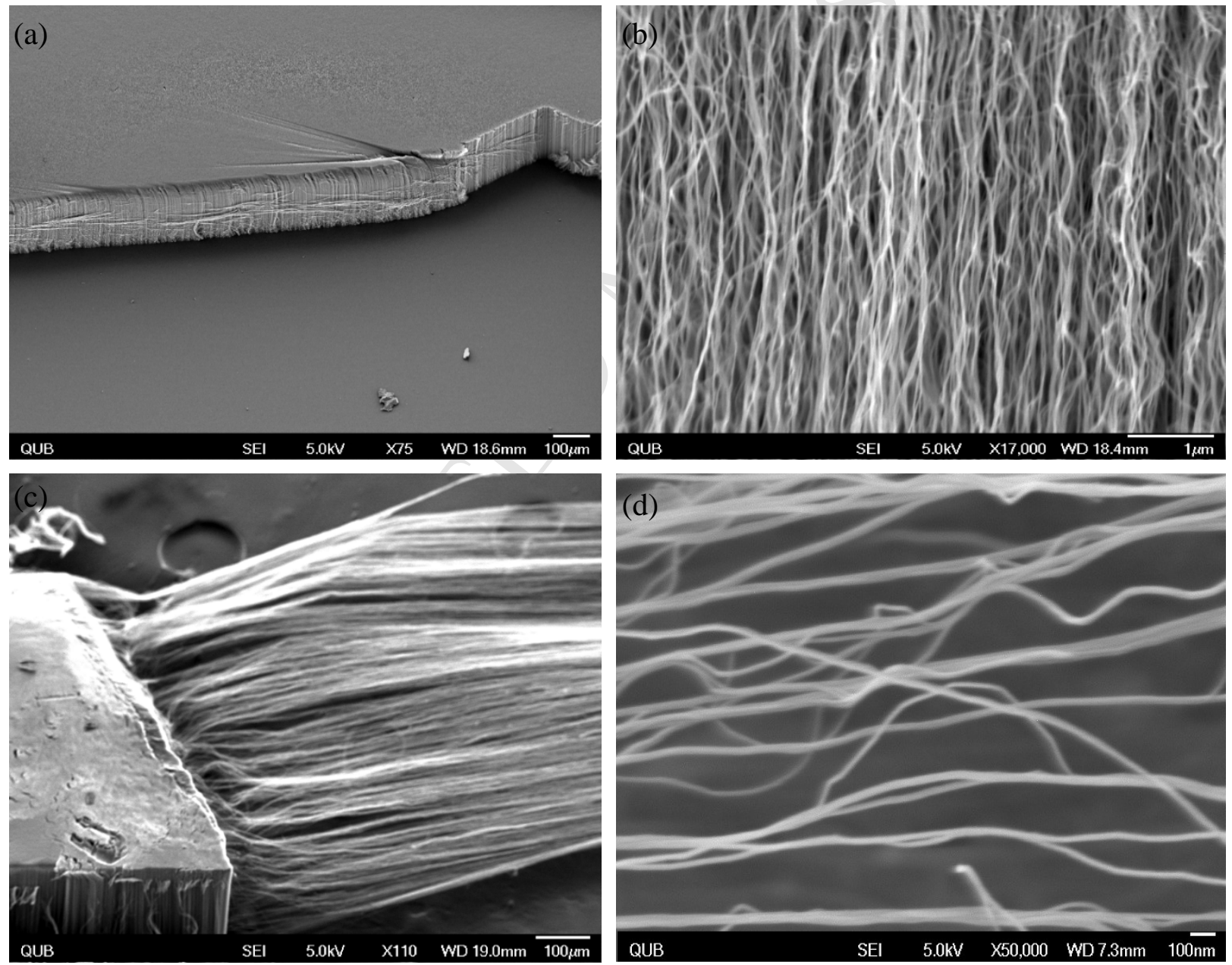

Fig.5: (a) FESEM image of drawable vertically aligned CNT arrays (b) high magnification image of highly aligned CNTs (c) capturing of drawing of CNT-SLW from CNT arrays grown over Si wafer (d) high magnification image of horizontally aligned CNT-SLW. 

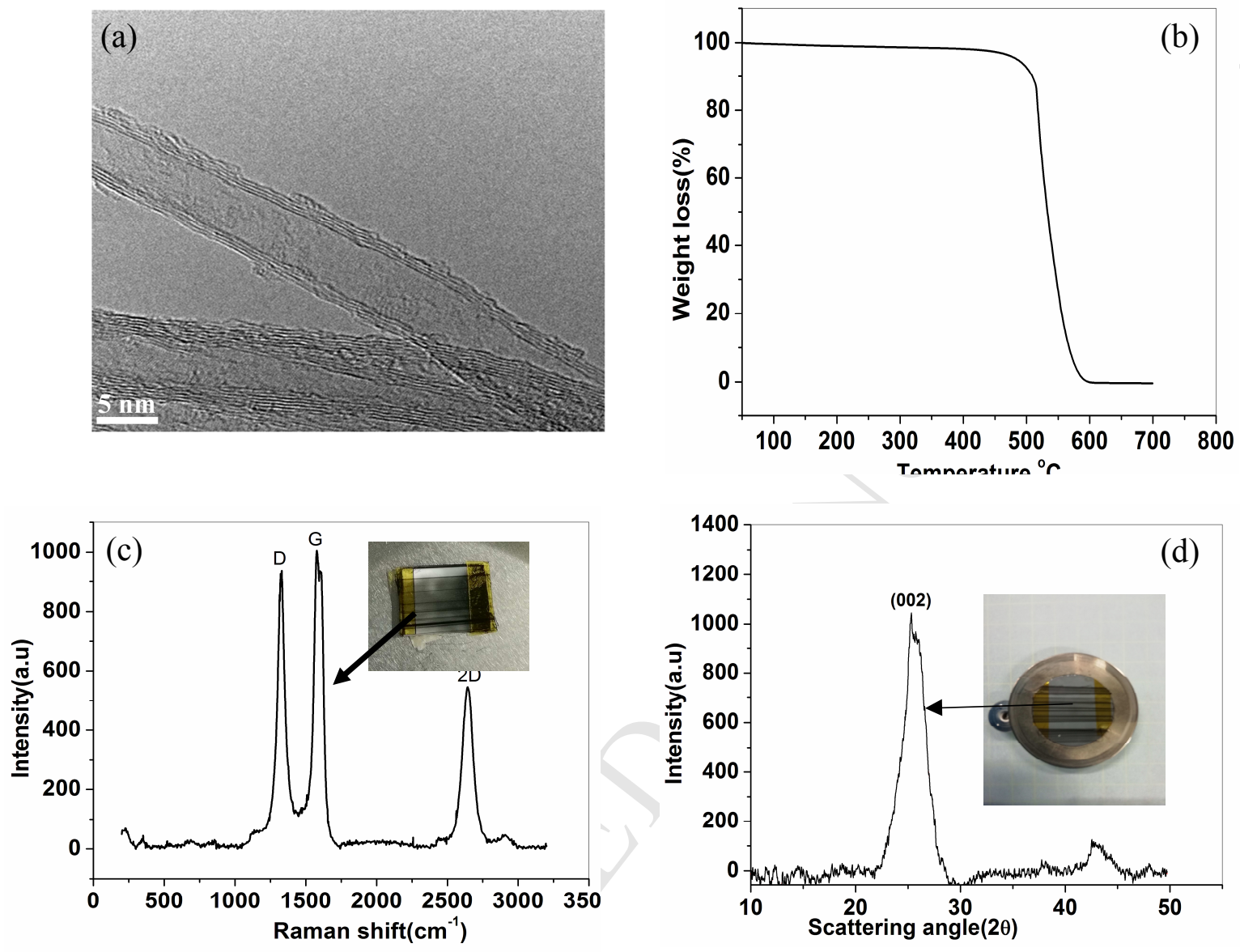

Fig.6: Characterization of CNTs (a) HRTEM image of CNTs from forest, (b) TGA of analysis of CNTs (c) Raman spectra of CNT-SLW and (d) XRD spectra of CNT-SLW. Inset digital images show the CNT-SLW

The Raman spectra of the CNT-SLW (Fig.6c) show two main distinct peak of D band and G band at $\sim 1334$ and $1573 \mathrm{~cm}-1$, respectively and the second-order peak of D at $2700 \mathrm{~cm}-1$. The $\mathrm{G}$ band corresponds to the characteristic tangential stretch mode of graphite wall, which indicates the presence of crystalline graphitic carbon in the CNTs. The D band corresponds to disordered graphite. The intensity ratio of D peak (ID) to G peak (IG) is a measure of the structural defects and amount of disorder in the carbon nanotubes. The relative intensity ratio 
of ID/ IG of the carbon nanotubes in this experiment is smaller than 1, which suggests less defect content in the CNTs [27]. Fig. 6d shows the typical XRD pattern of the CNT-SLW. The presence of the strongest diffraction peak at $25.3^{\circ}$ corresponding to the interlayer spacing of $0.34 \mathrm{~nm}$ and (002) reflection of the hexagonal highly ordered graphite structure [28-29]. The electric conductivity of CNT-SLW along the drawing direction (longitudinal) is about $2.6 \times 10^{3} \mathrm{~S} / \mathrm{m}$ [29]. It is of significance to mention that the inherent conductivity of nanofillers is a key factor in sensing. The further in-depth information on the detailed characterization of CNT webs such as degree of alignment, internal structures and mechanical properties can be obtained in previous reports from our group [26, 30-32].

Representative plots of load versus displacement for the unmodified joint and for joints containing a CNT-SLW parallel or perpendicular to the load direction show a slight increase in joint stiffness in the latter (Fig. 7a) and in lap-shear strength (Fig. 7b).
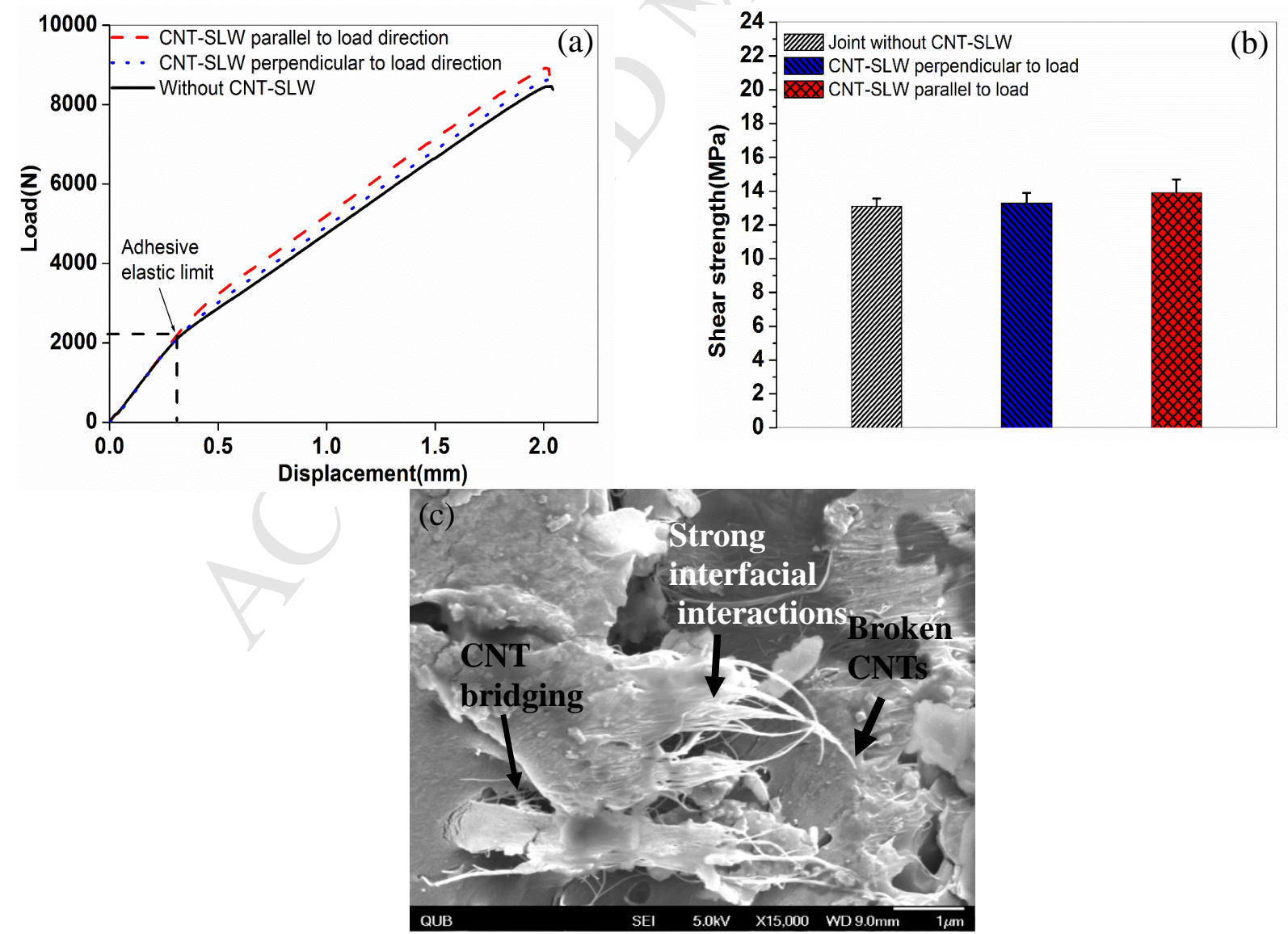
Fig.7: (a) Representative load vs displacement curves for adhesively bonded joints with embedded CNT-SLW (b) shear strength of joints (5 samples tested per configuration) and (c) fractured surface of CNT-SLW embedded joint.

The increase of strength can be ascribed to the interfacial bonding and crack bridging effects of aligned CNTs. The micro-structural examination of the fractured joints (Fig.7c) clearly reveals the strong CNT bridging effect during crack propagation. The presence of broken CNTs indicates a good bonding between the aligned CNTs and the surrounding adhesive matrix that lead to enhancement in the mechanical properties.

This increase is not statically significant but indicates that there was no appreciable change in the joints' structural performance. However, the load-displacement curves exhibit a bi-linear response, reflecting a change in stiffness, and this behaviour is consistent with other published works on similar adhesive joints $[33,19]$. The second region with a lower slope can be attributed to the plastic deformation of the adhesive. Fig. 8 shows a selection of images of the failed joints. All the fractured surfaces with and without CNT-SLW appear identical with adhesive found on both sides which confirms cohesive failure.

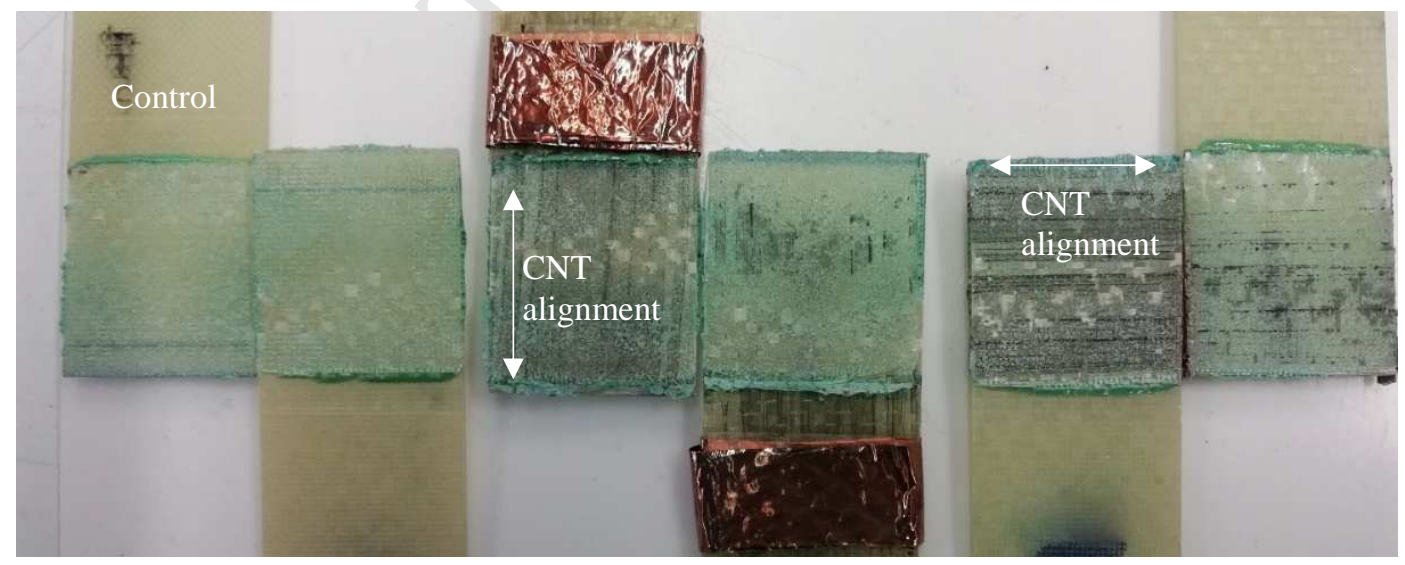

Fig.8: Fractured surfaces of adhesively bonded joints with embedded CNT-SLW. 
Fig. 9 shows the relative resistance change curves of the adhesively bonded joints embedded with CNT-SLW under quasi-static load. The CNT-SLW perpendicular to the load direction shows no significant resistance change (i.e. low $\Delta R / R_{o}$ ) compared with that for the parallel direction.

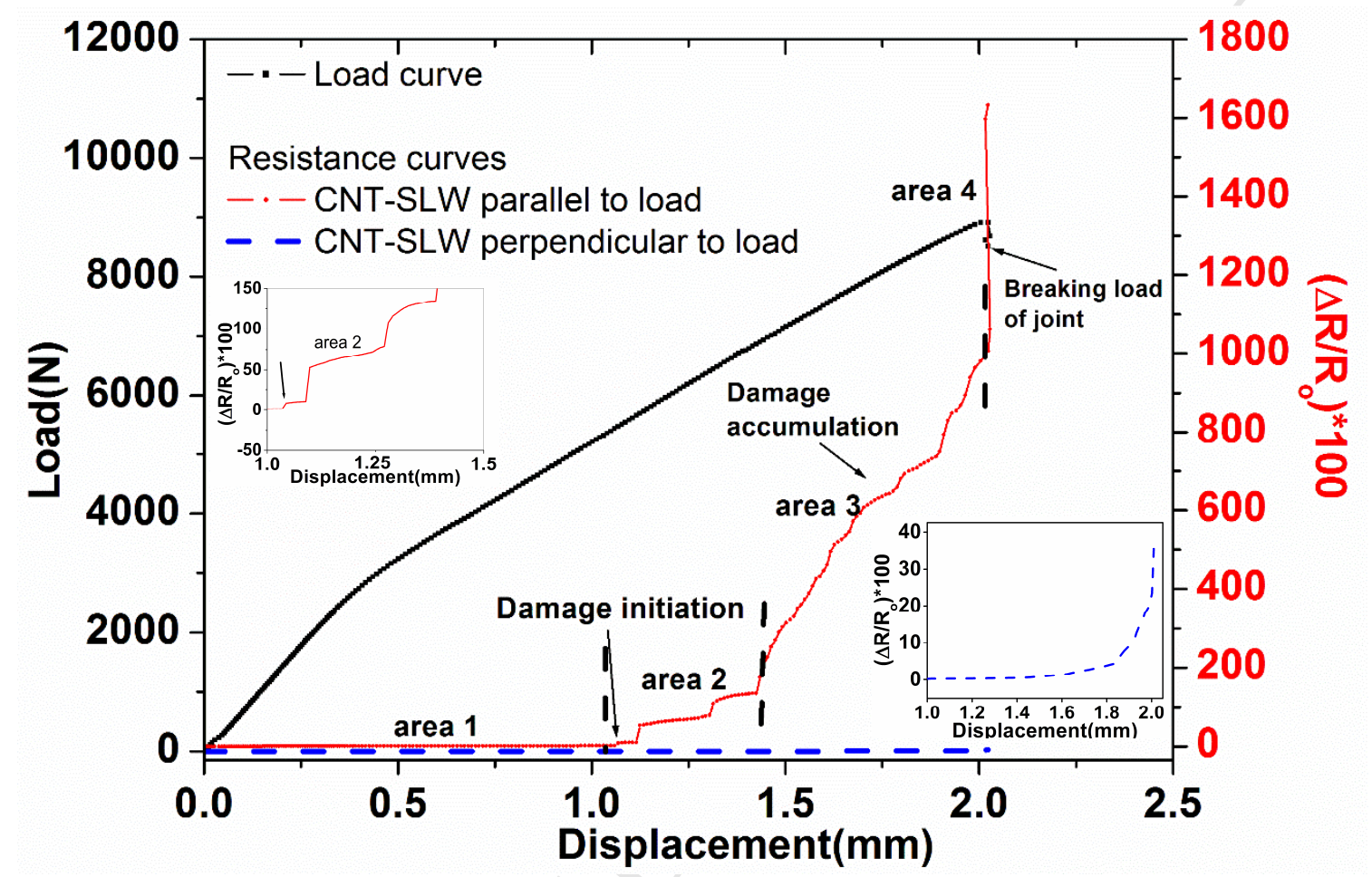

Fig.9: (a) Electrical resistances of adhesively bonded joints with embedded CNT-SLW under quasi-static load. Inset images shows a magnified version of the response of the CNT-SLW parallel (red/solid line) and perpendicular to load direction (blue/dotted line).

The distinct response of CNT-SLW parallel to the load direction is characterized by two transitions. The first occurs at a displacement of about $1.03 \mathrm{~mm}$, which registered the onset of damage initiation ( $1^{\text {st }}$ warning zone) by a sudden step increase in resistance (Inset Fig.9), below which the resistance change approximates a flat line. When the end-displacement reached $\sim 1.38 \mathrm{~mm}$, the resistance exhibits an exponential increase $\left(2^{\text {nd }}\right.$ waring zone $)$ until the resistance of the sensor exceeds the detection limit of the instrument. In the whole measuring process, from damage initiation to the failure of the joint at around $2 \mathrm{~mm}$ displacement, the 
relative resistance change $\Delta R / R_{o}$ jumps to $\sim 1631 \%$. To the authors' best knowledge, this relative resistance change, with progressive damage, is significantly higher than results reported in the literature for sensors based on dispersed CNTs/graphene in an epoxy adhesive [17-24, 34-37].It indicates that preferential orientation of carbon nanotubes seems to be critical to differentiate microscale damage with respect to load direction. We also compared our results with recently reported studies on sensors based on aligned CNTs (Table 1). The performance comparison shows that the CNT-SLW has excellent electrical resistance response to deformation. This is governed by (i) strong interfacial bonding between CNTs and the adhesive matrix which results in very effective load transfer to the CNTs, harnessing the piezoresistive properties of the CNTs, and (ii) the high degree of alignment of the CNTs within the web, causes significant changes in contact area between CNTs upon crack opening and widening [38-43].

Table 1: Comparison of sensitivity to progressive damage of our sensor with that of other sensors based on aligned CNTs.

\begin{tabular}{|c|c|c|}
\hline Aligned CNT sensors & $\begin{array}{c}\left(\Delta \mathrm{R} / \mathrm{R}_{\mathrm{o}}\right) * 100 \\
\text { close to failure }\end{array}$ & Reference \\
\hline Aligned CNT sheet reinforced GRRP composites & $40 \%$ & 38 \\
\hline Aligned CNTs sheet reinforced epoxy composites & $8 \%$ & 39 \\
\hline Aligned MWCNT sheet -PDMS sensors & $1200 \%$ & 40 \\
\hline Aligned CNT-PDMS sensors & $500 \%$ & 41 \\
\hline Aligned CNT-PDMS & 1500 & 42 \\
\hline Printed CNT-PDMS sensors & $1700 \%$ & 43 \\
\hline Aligned CNT web embedded adhesive joints & $1633 \%$ & This work \\
\hline
\end{tabular}

In contrast, the CNT-SLW perpendicular to the load direction showed only a $\sim 37 \%$ increase in relative resistance $\left(\Delta R / R_{0}\right)$ and only close to failure (Inset Fig. 9). Morphological studies were performed on the fractured surfaces of the joints to gain further insight into the sensing behaviour of CNT-SLW perpendicular and parallel to the load direction (Fig.10a and 10b).

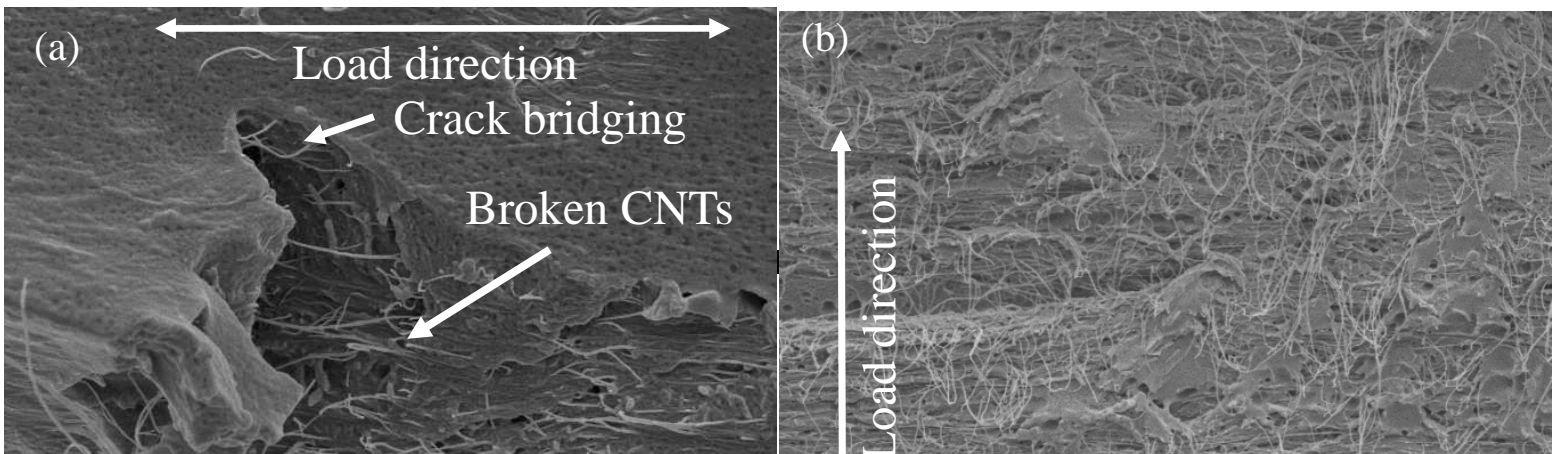


Fig.10: SEM image of fractured surface with (a) CNT-SLW parallel and (b) perpendicular to load direction.

Fig. 10a shows the formation of transverse micro-cracks to the load direction and the CNTSLW, parallel to the load, can be seen to interact with these cracks. This explains the large increase in resistance from initial damage to failure. In contrast, the CNT-SLW perpendicular to the load direction (Fig. $10 \mathrm{~b}$ ), seems to detach from the matrix during deformation and loses alignment. Due to the high aspect ratio of the CNTs, the broken contacts, or detached CNTs, form an 'electrical bridge' with adjacent CNTs that result in only a modest increase in resistance during continuous deformation. This confirms very limited deformation or load transfer to CNTs when they are oriented perpendicular to the applied load. It is also anticipated that a number of cracks will be aligned in the draw direction of the CNT-SLW. On the other hand, the significant shift in resistance for a CNT-SLW, parallel to the load direction, confirms the formation of transverse cracks and the means of detecting damage. These results are consistent with other works published on externally-mounted aligned CNT sheets with respect to a tensile loading direction [44-46].

To better understand, the distinct damage-sensing mechanisms along parallel and perpendicular directions mentioned above (Fig.9), a simplified electrical resistance network model is proposed:

$$
\mathrm{R}_{\mathrm{total}}: \mathrm{R}_{\mathrm{CNT}}+\mathrm{R}_{\mathrm{c}}
$$


Where $\mathrm{R}_{\mathrm{CNT}}$ is the intrinsic resistance of the CNT and $\mathrm{R}_{\mathrm{c}}$ is the contact resistance when the two CNTs are completely overlapping, such that the distance between centres of two CNTs is comparable or less than the diameter of a CNT [47]. Based on the CNT-SLW fabrication process and highly overlapped morphology, the resistance change at the CNT-CNT junctions seems to be the main damage sensing mechanism. Initially, under zero loading state, the contact resistance is mainly caused by the tunnelling effect among CNTs. Thus, when subjecting a joint to continuous loading, a relatively flat relative resistance curve is seen with applied displacement below $1.03 \mathrm{~mm}$ (area 1, Fig. 9). The resistance increases very slowly with increasing displacement below this point, which means that CNTs are still maintaining direct contact but only contact area is changing between CNTs(slippage between adjacent CNTs and it is assumed that the tunnelling distance (d) remains constant, similar to the zero loading state (area 1). However, after that first step-change in resistance, followed by step increases between an end-displacement of 1.03 and $1.38 \mathrm{~mm}$, it is proposed that a considerable number of CNTs still bridged across the cracks, making the conducting pathways still viable through increasing tunnelling in addition to partial breaking of a few conductive paths (area 2, Fig. 9).

However, after an end-displacement of $1.38 \mathrm{~mm}$ (area 3, Fig. 9), resistance follows an exponential change, indicating the increasing presence of disconnected CNTs, leading to fewer conductive pathways. The significant change in resistance during macro-damage accumulation confirms that electrons can no longer be transferred between the CNTs ( $d$ is exceeded beyond tunnelling cut-off distance) due to stochastic breakage of CNT contacts. In area 4 (Fig. 9), at a displacement of $2 \mathrm{~mm}$, resistance jumps abruptly to an infinite resistance change, indicating catastrophic rupture of the CNT-SLW. Fig. 11a is a diagrammatic representation of the response of the CNT-SLW, parallel to the load direction, under a monotonically increasing axial load. 
In contrast, the CNT-SLW transverse to the load direction demonstrates distinct behaviour with a very low resistance change up to joint failure $(\sim 37 \%)$ and negligible resistance change before $1.8 \mathrm{~mm}$ end-displacement, as confirmed by Fig.9. Below an end-displacement of 1.8 $\mathrm{mm}$, the transverse stretching of the CNT-SLW did not induce any significant changes to the contact conditions of the CNTs (Fig. 11b). The change of slope and modest resistance increase, just prior to failure, suggests an increase in the tunnelling gap whilst maintaining a practically constant level of CNT-CNT connections $[45,48]$.

CNTs-SLW integrated into adhesive matrix

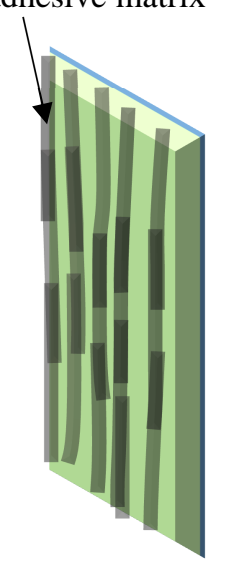

Zero displacement /Load

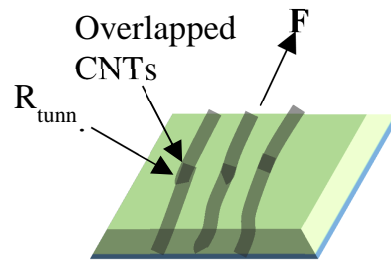

Displacement $<1.03 \mathrm{~mm}$.
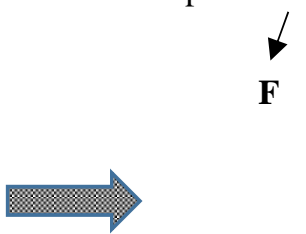

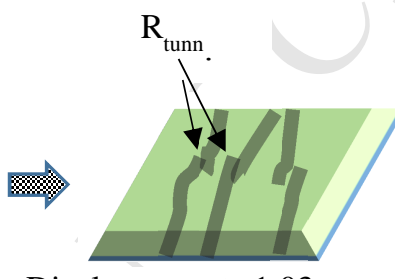

Displacement $\geq 1.03 \mathrm{~mm}$. Increased tunnelling gap and reduced number of CNT-CNT contacts.

(a)

)

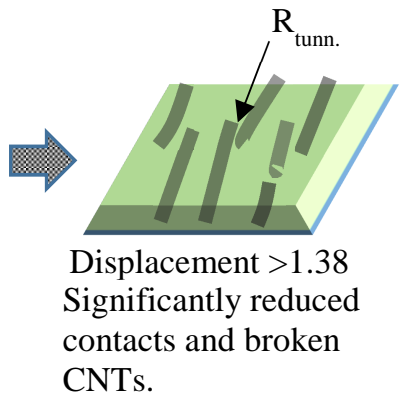

CNTs.
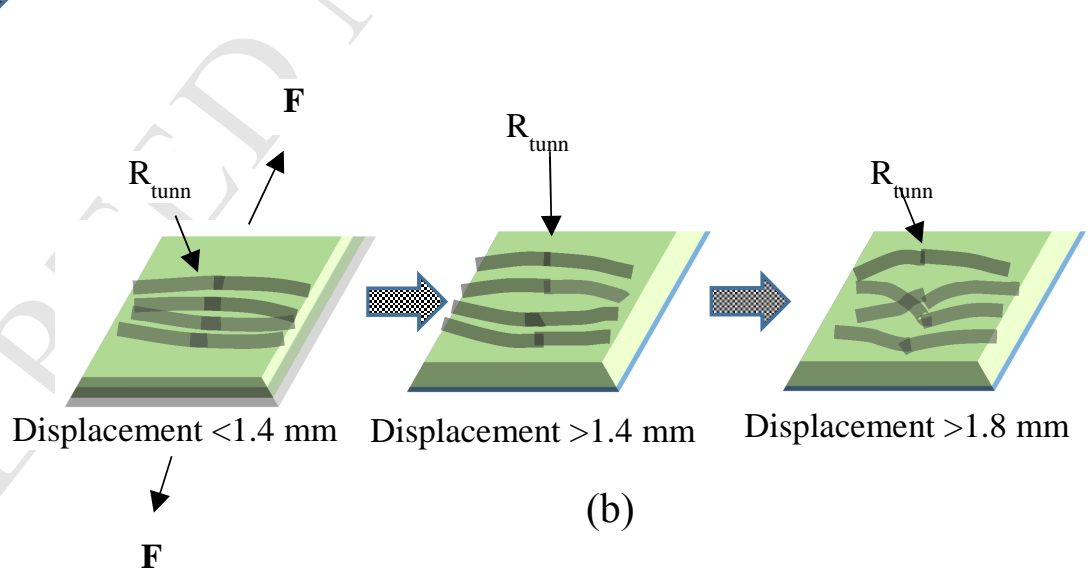

Displacement $>1.8 \mathrm{~mm}$

(b)

Fig.11: Representation of the damage sensing mechanism for CNT-SLW (a) parallel and (b) perpendicular to load direction with increasing end-displacement (deformation).

To demonstrate the stability and sensitivity to new damage accumulation, the CNTSLW/adhesive joints were investigated at different cyclic displacements, with maximum displacements below and above that for which damage initiation was observed $(1.03 \mathrm{~mm})$ as indicated in Fig. 9. Samples cyclically loaded to a displacement from $0.1 \mathrm{~mm}$ to $0.5 \mathrm{~mm}$ (i.e. 
$\mathrm{d}=0.2$, where the maximum displacement is below the damage initiation loading) show (Fig.

12) that, after an initial stabilising phase, the resistance is fully recoverable in each subsequent cycle with negligible drift or hysteresis. The change $\Delta R / R_{0}$ is almost constant at almost $4 \%$ and curves follow the applied displacement without any lag. The small steady rise in resistance at $0.5 \mathrm{~mm}$ displacement ( $1.0 \%$, from cycle 1-5) and undulations observed after the fifth cycle may be due to the rearrangement of CNTs under load $[12,14]$.

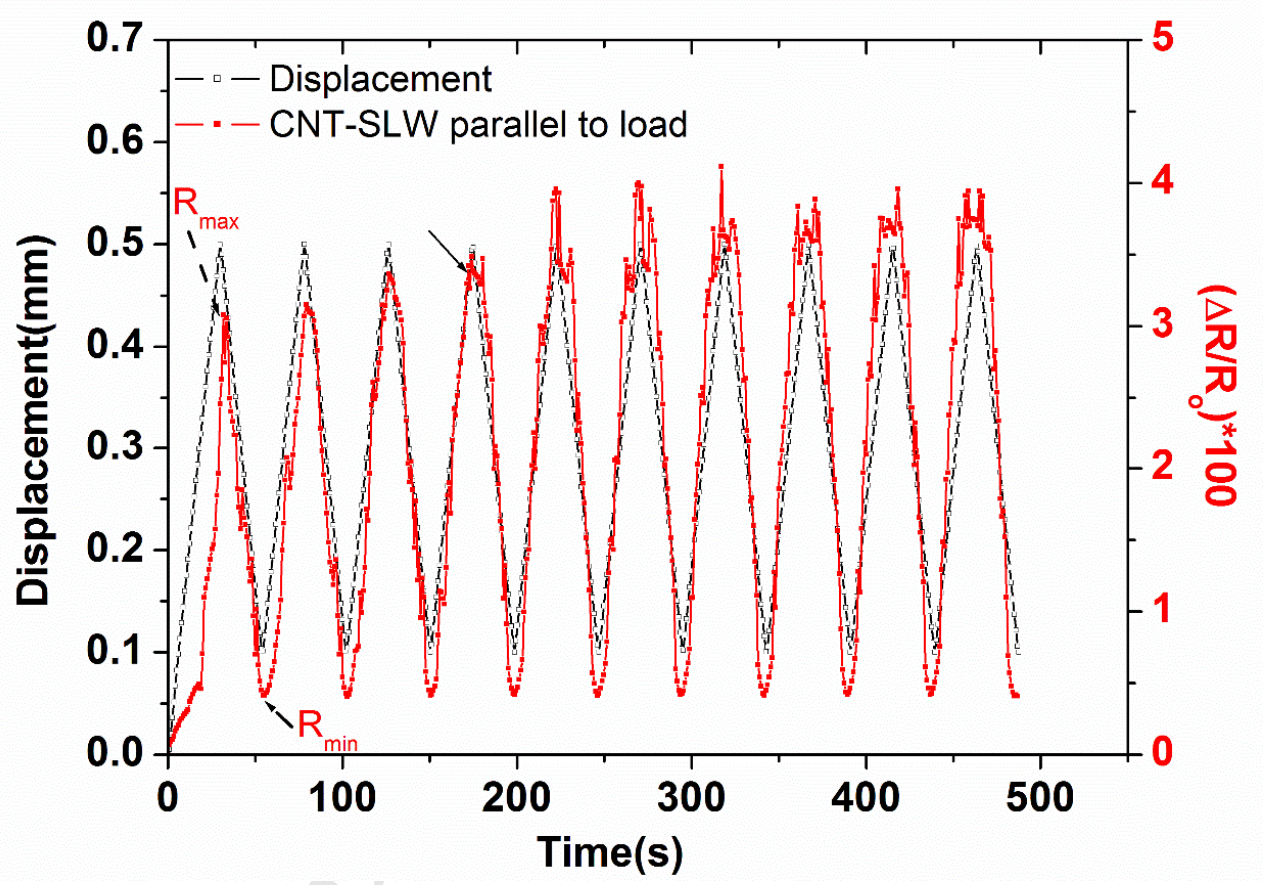

Fig.12: Sensor response below damage initiation.

The joints were subsequently exposed to three different levels of displacement cycles with a maximum displacement beyond that which resulted in damage initiation. For a maximum displacement of $1.1 \mathrm{~mm}$ (just after damage initiation, Fig. 13) and a peak-to-peak displacement amplitude of $1.0 \mathrm{~mm}$, not only was a linear resistance response observed, but also a positive increase of resistance over the cycles. The gradual increase in cyclic resistance ( $\mathrm{R}_{\max } \sim 9 \%$ from cycle 1-10) can be related to increased tunnelling gaps between CNTs with increase of size of pre-existing cracks (cycle 2-9). The change in the slope of $\Delta R / R_{0}$, at the 
tenth cycle, indicates the accumulation of new damage, and confirms the high sensitivity of CNT-SLW to cracks at any length scale [2]. The constancy of the $\mathrm{R}_{\min }$ value despite the rising $\mathrm{R}_{\max }$ value demonstrates that the release of the load allows re-connection of the broken or separated CNTs with essentially unchanged fidelity as the incipient fractures close. The aligned CNT architecture facilitates the return of CNTs back to their original position through their defined paths, without buckling on contraction.

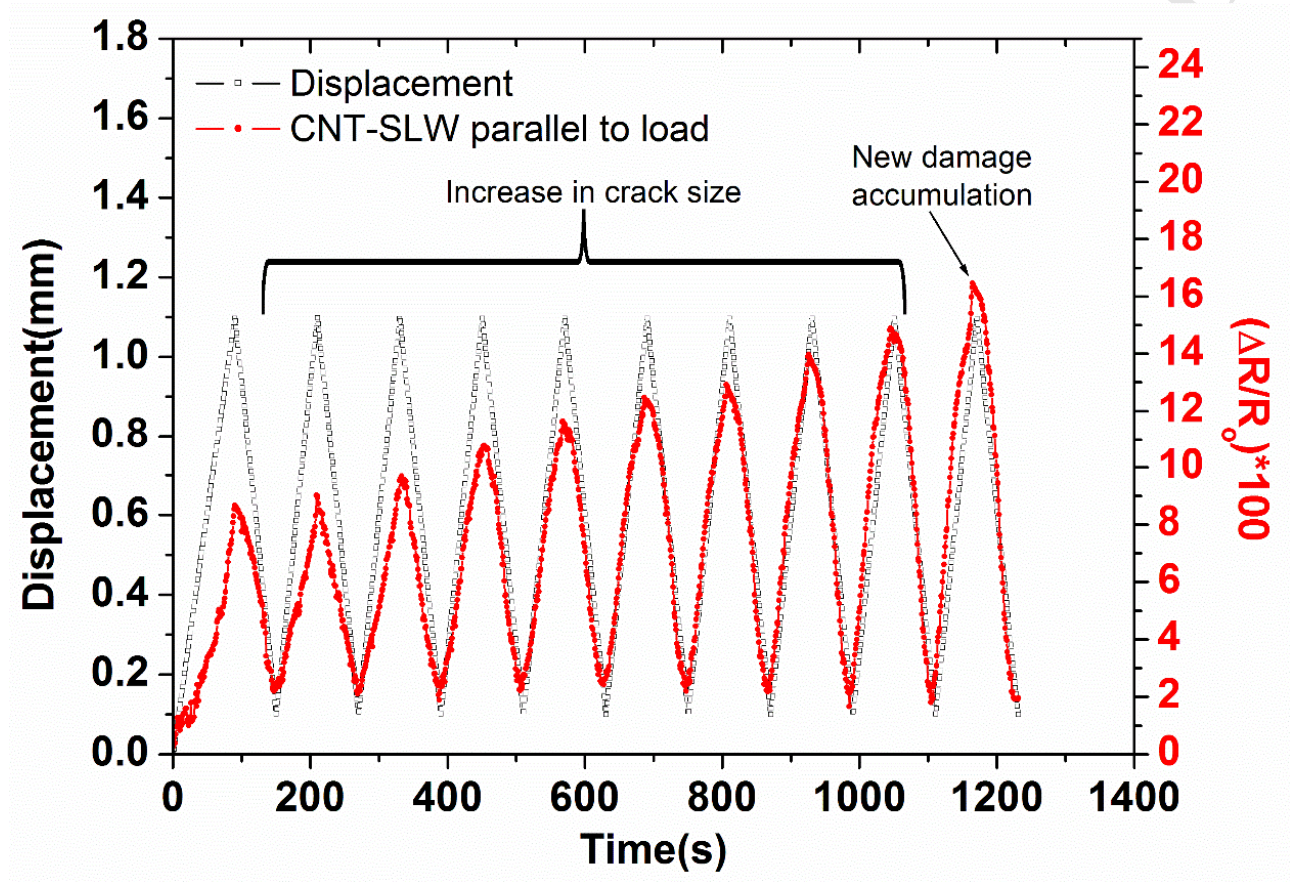

Fig.13: Sensor response at a maximum end-displacement just above the damage initiation threshold.

Fig. 14a shows another example where the samples were subjected to a maximum displacement of $1.5 \mathrm{~mm}$. The CNT-SLW sensor showed highly sensitive behaviour to cyclic damage accumulation. As confirmed by Fig. $14 \mathrm{a}$, the resistance $\left(\mathrm{R}_{\max }\right)$ shows a linear increase from cycle 1-10 ( 700\%) confirming the coalescence of multiple micro-cracks under cyclic displacement. The large resistance increase is associated with the disconnection of a large number of CNTs within the CNT-SLW. Notably, the excellent recovery of resistance on release, confirms the high flexibility and large strain of the CNT web. The cyclic stability and 
sensitivity behaviour of the CNT-SLW is better than conventional CNT/polymer composites at comparable deformation levels. Conventional CNT-based composites suffer from irreversible changes in resistance during cyclic loadings, due to the irreversible breaking of inter-nanotube connections $[8,15,34]$. The enlarged image of the third cycle (Fig. 14b) shows that additional information such as crack re-opening, elastic deformation and accumulation of new damage, may be deduced from the changes in the slope of the resistance curve during the rising part of the loading cycle. These findings are consistent with previous work reported by Gao et al. on CNT/fibre reinforced composites [8].

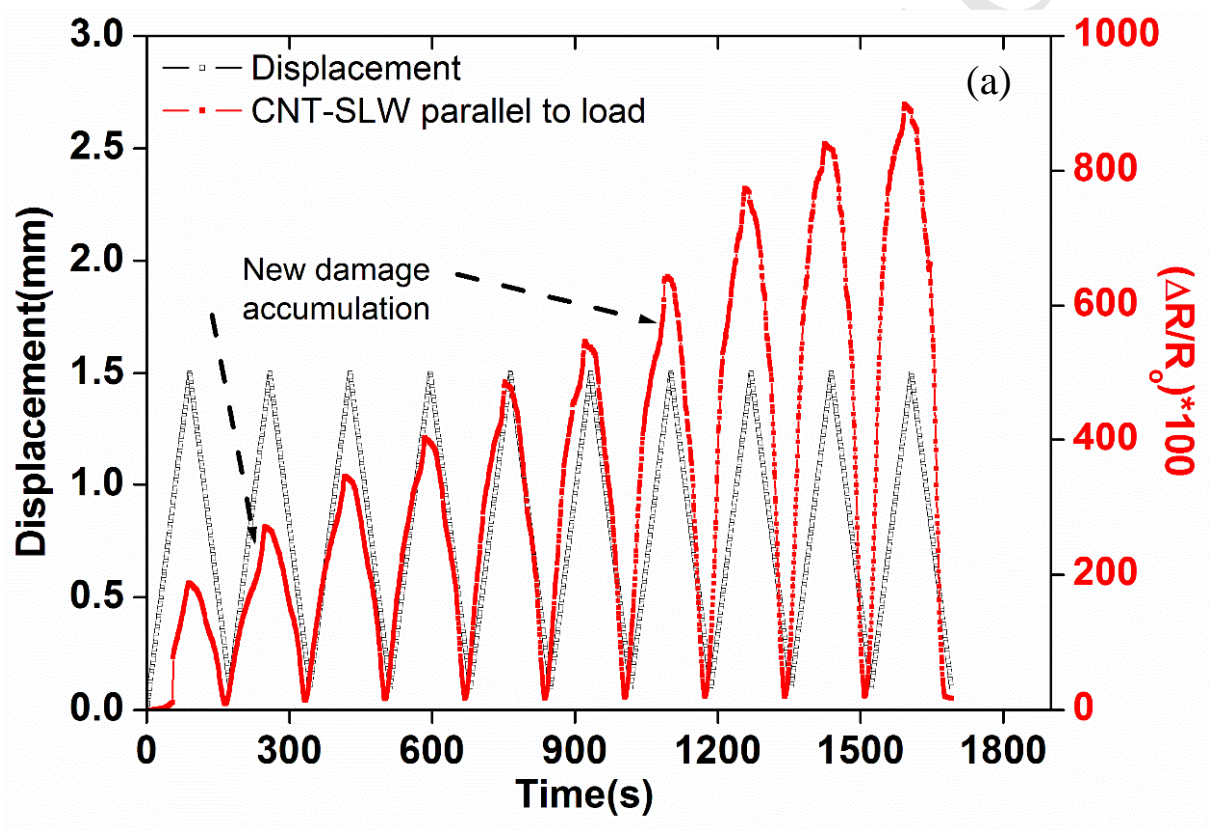




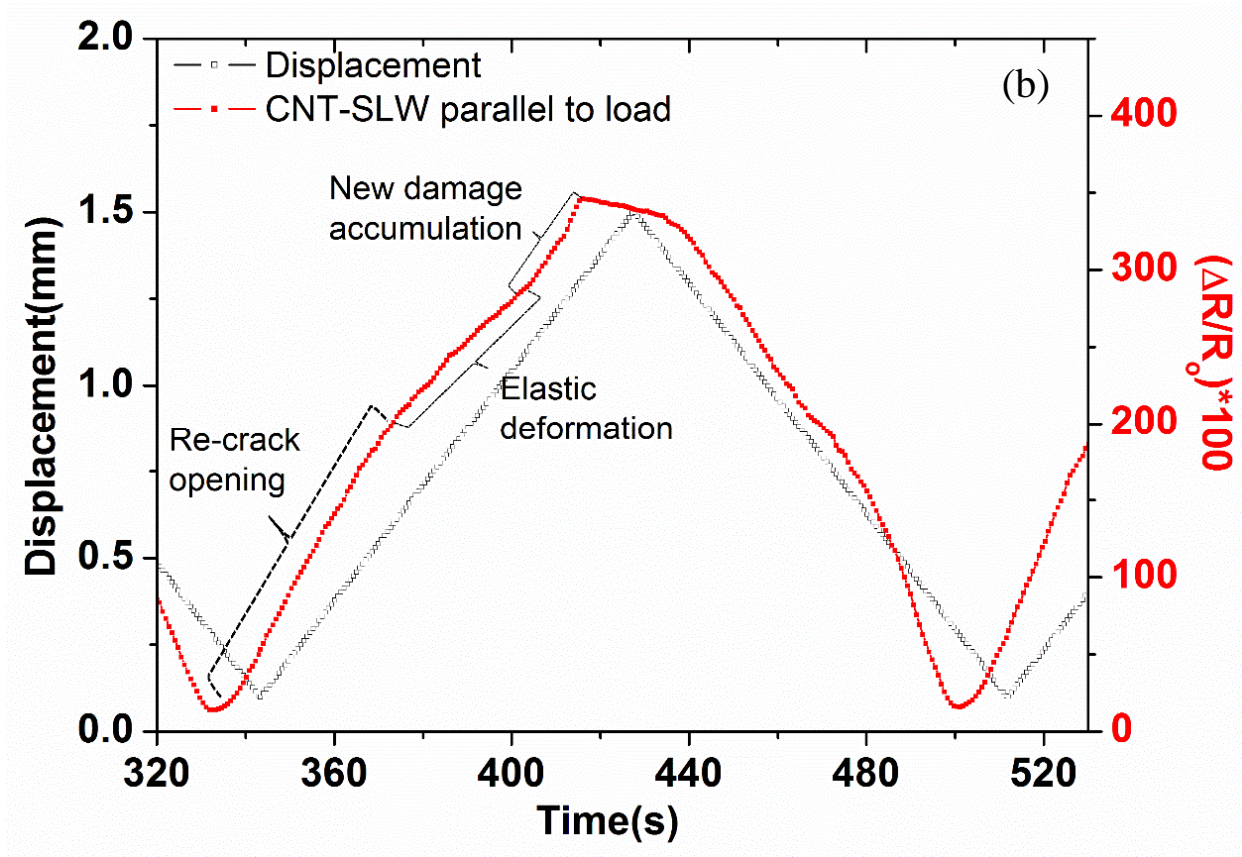

Fig.14: (a) Sensor response at a maximum end-displacement well above the damage initiation threshold and (b) Expanded view of subsequent cycle highlighting the re-opening of a crack and formation of new damage.

Cyclic failure of composites joints may be a combination of different failure mechanisms such as cohesive/matrix cracking, delamination and fibre-matrix debonding. Identification of these different mechanisms can be difficult, however the present study reveals remarkable mapping of different damage mechanisms leading to cyclic failure. 

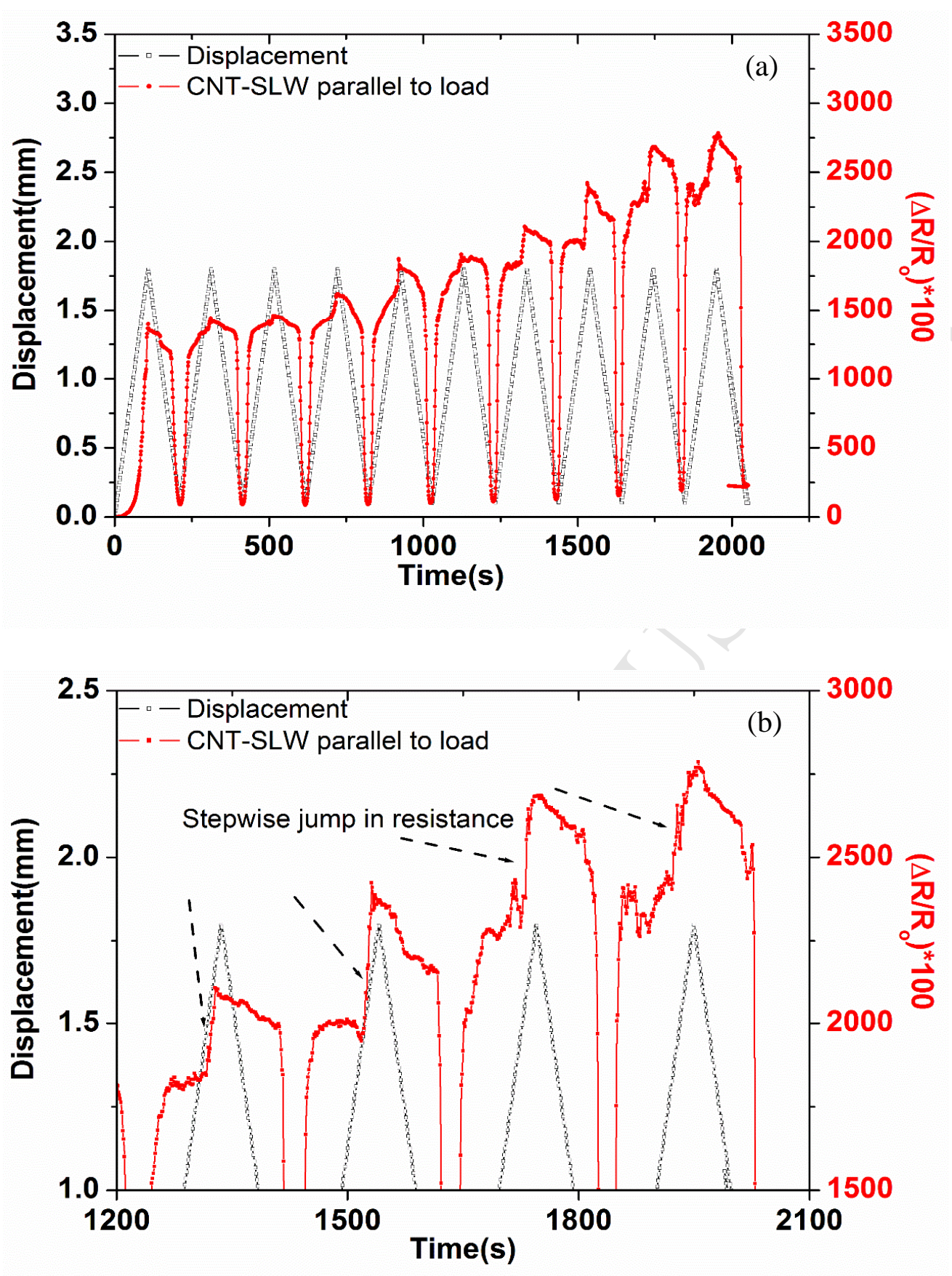

Fig.15: Sensor response at a maximum end-displacement just below that recorded at failure for the quasi-static loading.

It is seen in Fig. 15a that damage accumulation increases gently up to the third cycle, with full recovery of lower resistance upon unloading, and then increases more rapidly. The overall resistance increase up to the third cycle $(\sim 1621 \%)$ almost falls in the range of cohesive failure ( 1631\%, Fig.8 and Fig.9).Therefore, damage accumulation (in Fig.15a) up to the 
third cycle could be regarded as macro-level adhesive matrix damage. The much higher distinguishable step-wise jump in resistance, beyond the sixth cycle (Fig.15b), can be associated with fiber breakage and fibre-matrix debonding [10]. At this stage, it is expected that matrix cracks reach and propagate through the adhesive matrix/ fibre interface causing significant damage. Notably, a closer view from the fourth cycle onwards, reveals an irreversible drift of resistance that can be related to the destruction of the CNT-SLW aligned network due to abrupt fibre/matrix interface failure of the cyclic fractured joint surface [12, 49]. These contrasting failure mechanisms are well manifested by microscopic images of the cyclic fractured joint. Fig.16 confirms the adhesive matrix cracking as well as major destruction of the CNT-SLW conductive pathways (black circle) induced by delamination, fiber breakage and fiber/matrix debonding (indicated by red arrow).

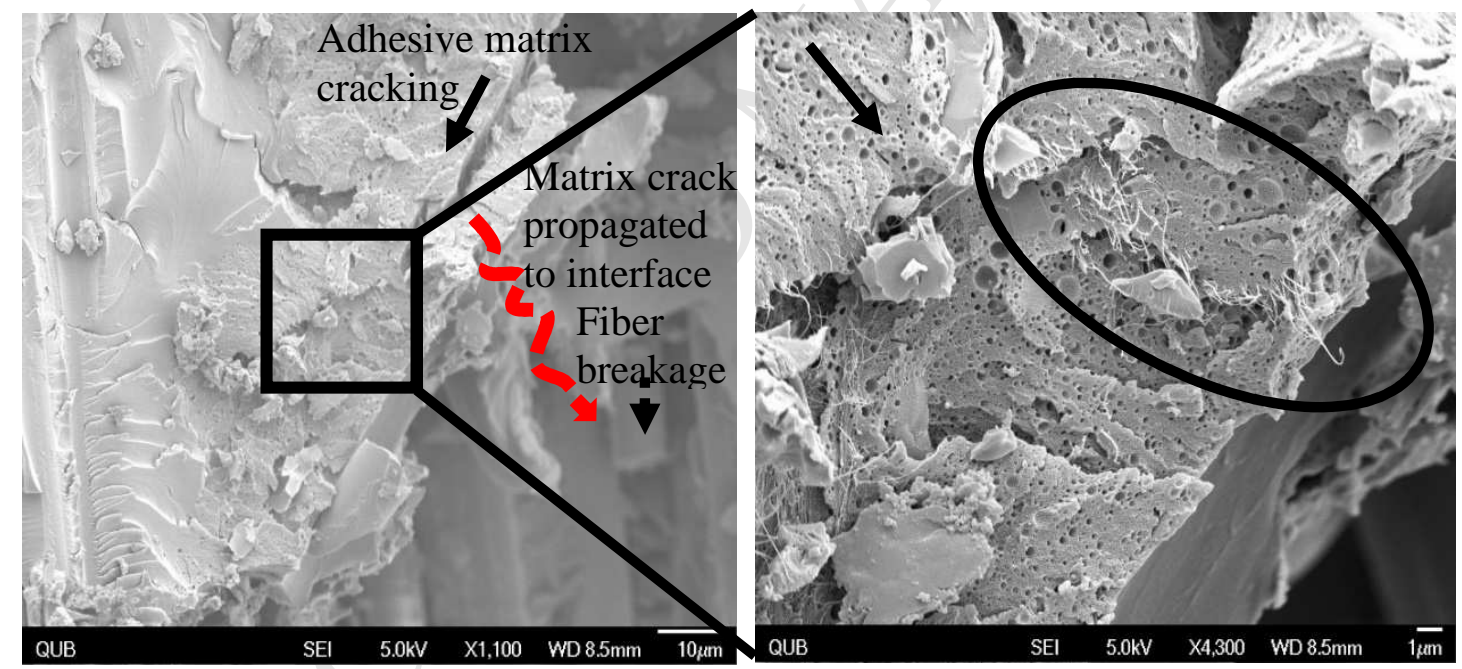

Fig.16: SEM image of fractured joint showing different failure mechanisms during cyclic loading.

Load control experiments were also conducted with peak loading close to the strength of the joint to assess the sensing response of CNT-SLW parallel and perpendicular to the applied load. 

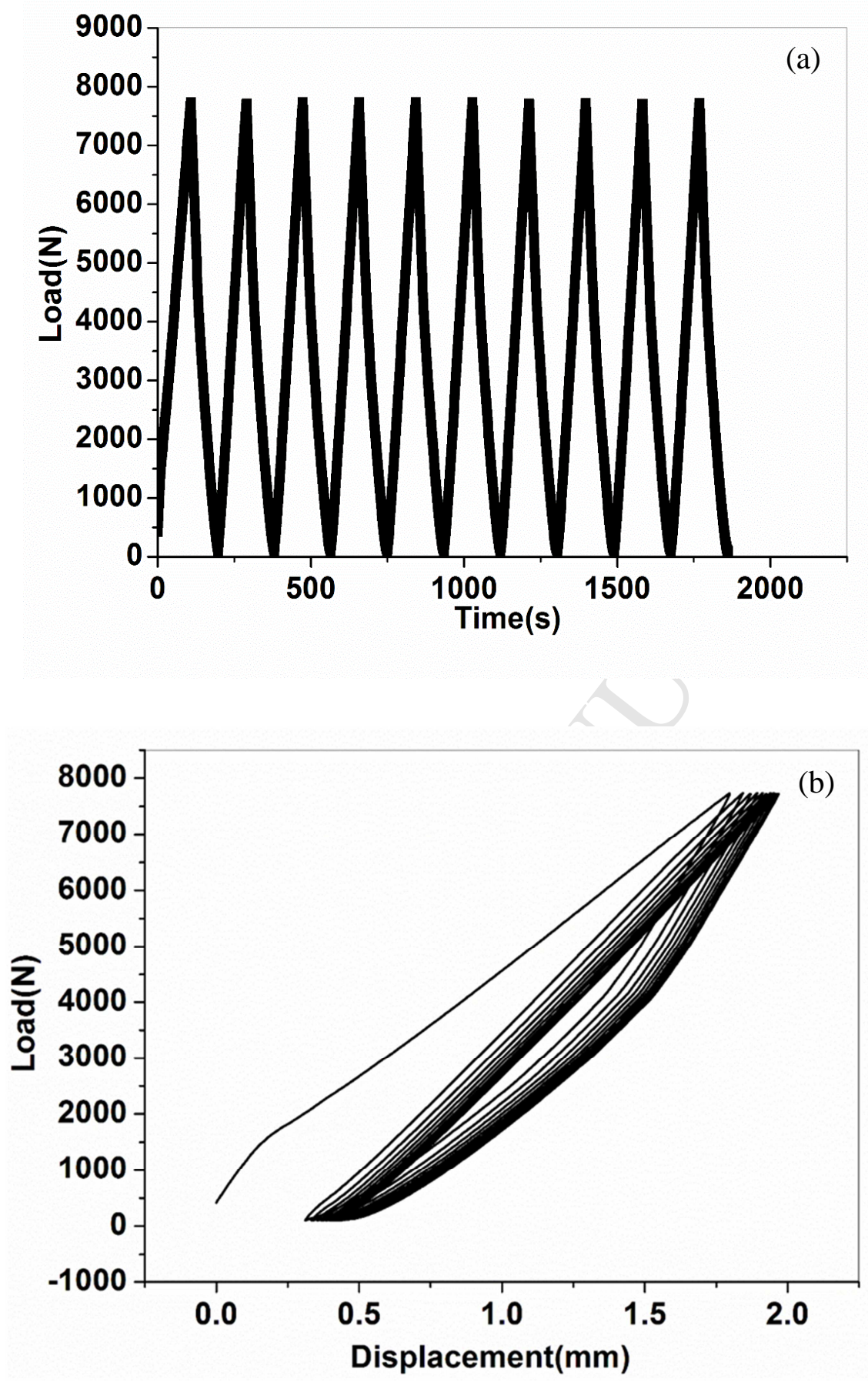

Fig.17: Cyclic load curve as (a) function of time (b) displacement between $100 \mathrm{kN}$ and 7740 $\mathrm{kN}$.

Fig. $17 \mathrm{a}$ and $17 \mathrm{~b}$ show the representative curves for cyclic loading as a function of time and displacement respectively. The specimens were cycled between $100 \mathrm{~N}$ and $7740 \mathrm{~N}(90 \%$ of the quasi-static breaking load). An increasing displacement with each subsequent cycle, indicates a viscoelastic response. 


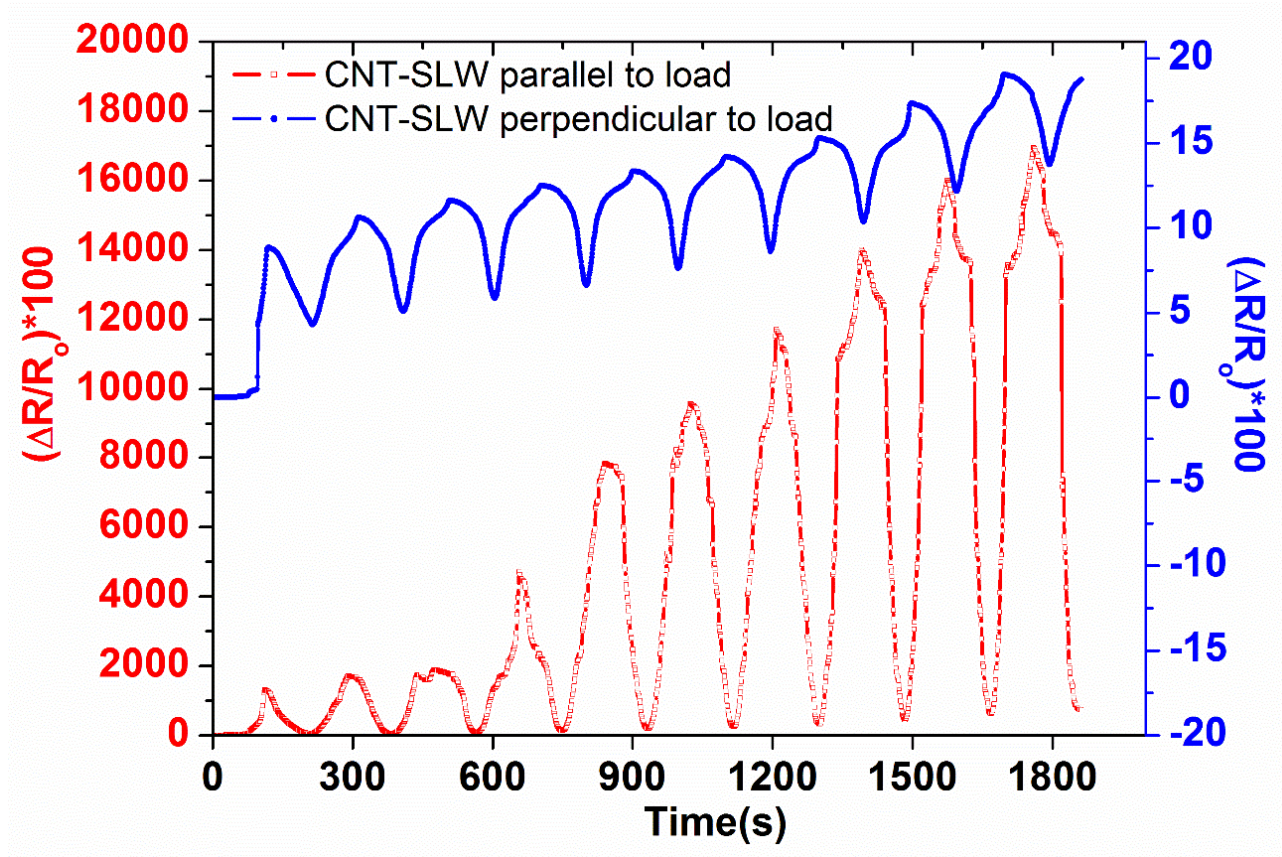

Fig.18: Sensor response to cyclic loading $(100 \mathrm{kN}$ to $7740 \mathrm{kN})$

As expected, the damage accumulation response during cyclic load-control experiments follow a similar trend to those of displacement-control (cf. Fig. 17 and Fig. 15). For example, an initial modest increase over the first three cycles followed by a linear increase from the fourth cycle onwards. Note that, as expected, the damage accumulation is much more severe in load-control ( $\mathrm{R}_{\max } \sim 15000 \%$ increase, cycle 1-10) than for joints tested under displacementcontrol ( $\mathrm{R}_{\max } \sim 1400 \%$, cycle 1-10) where load relaxation takes place. More importantly, as shown in Fig. 19a, the combination of large increases in $\mathrm{R}_{\max }$ over the cycles and insignificant drift of $\mathrm{R}_{\min } \ll 4 \%$ (recoverable resistance,) is rarely reported. It seems that a well-integrated aligned CNT architecture enables CNTs to return to their original state upon unloading. Additionally, the viscoelastic behaviour of the adhesive matrix and the successful transfer of load from matrix to CNT-SLW could also help CNTs to re-arrange to their original network upon unloading. 

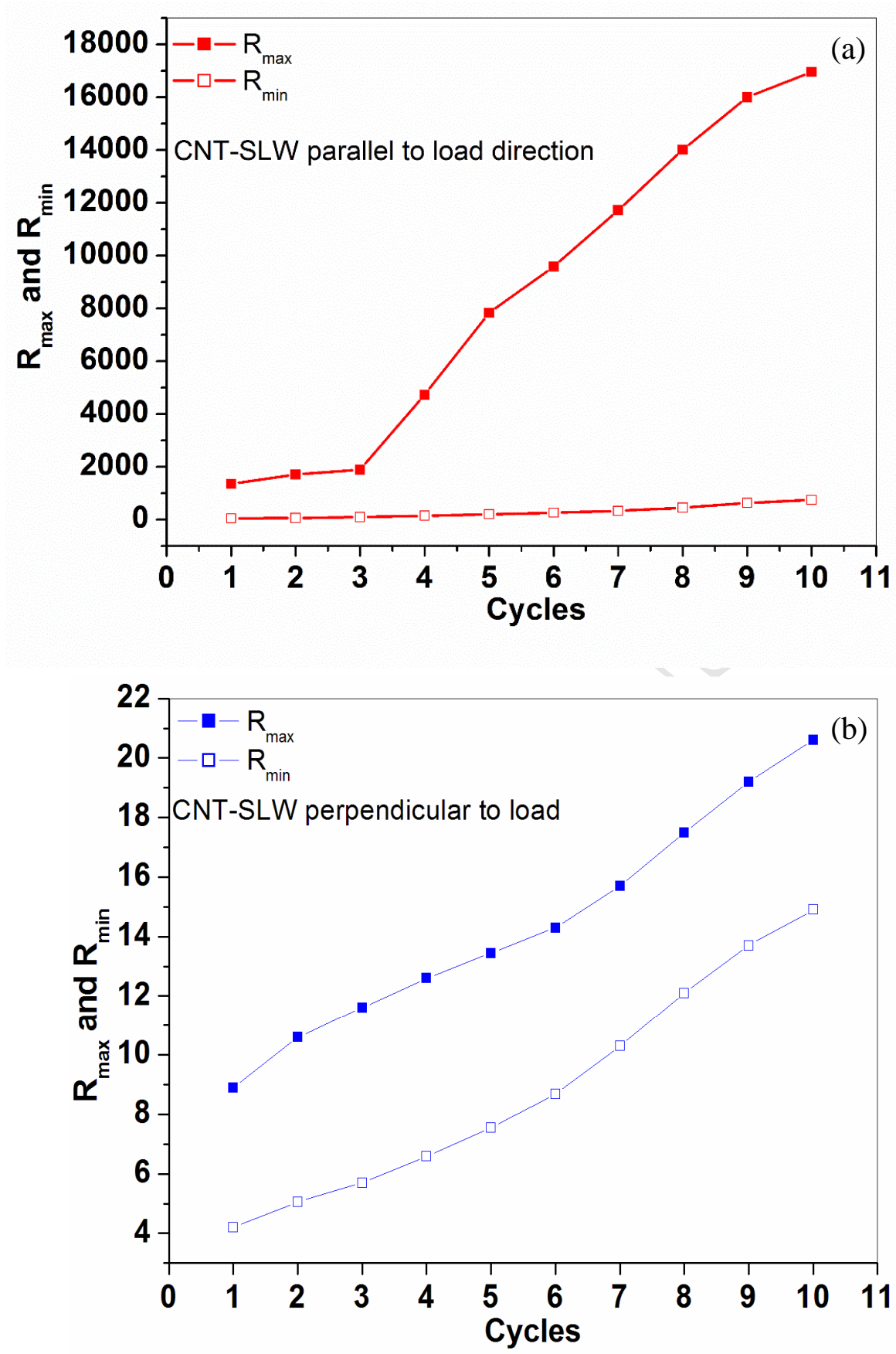

Fig.19: Changes in $R_{\max }$ and $R_{\min }$ with each cycle post damage initiation: (a) CNT-SLW parallel (b) perpendicular to load direction $(100 \mathrm{kN}$ to $7740 \mathrm{kN}) . \mathrm{R}_{\max }$ corresponds to the damage sensitivity and $\mathrm{R}_{\min }$ to recovery of resistance.

In contrast (Fig. 19b), for CNT-SLW perpendicular to load, the sensitivity to cyclic damage accumulation is poor. The scale of the change in $\Delta R / R_{0}$ is around two orders of magnitude 
lower than for the parallel orientation. Comparable drift of both $\mathrm{R}_{\max }$ and $\mathrm{R}_{\min }$ shows lower sensitivity and cyclic stability compared to CNT-SLW (parallel to load) for reasons described earlier.

This experimental study has demonstrated that macro-architectured CNT assemblies, in this case as a highly-aligned web, are capable of being deployed as ultrasensitive sensors with high sensitivity to micro-cracks and displaying excellent mechanical stability against repeated loading-unloading cycles.

\section{Conclusions}

In this work, we have presented a novel and single step approach for damage sensing in adhesively bonded joints using a highly aligned carbon nanotube single layer web (CNTSLW). of insignificant weight $(20 \mathrm{mg} / \mathrm{sqm})$ and a densified thickness of $50 \mathrm{~nm}$, which mitigated the problems and limitations encountered when dispersing CNTs in bulk resin for similar purposes. The capability of a CNT-SLW to monitor damage initiation and progression was thoroughly evaluated and the influence of the orientation of the CNT-SLW on sensitivity explored. When aligned with the load direction, the CNT-SLW sensor displayed remarkably high cyclic stability as well as exceptionally high sensitivity $\left(\Delta \mathrm{R} / \mathrm{R}_{\mathrm{o}} \% \sim 1629 \%\right)$ to damage accumulation and significantly higher than reported results for sensors based on CNTs/graphene dispersed in an epoxy adhesive. We believe that the present ultra-sensitive sensors based on a macroscopic highly-aligned architecture of CNTs have considerable potential for the development of high performance structural health monitoring (SHM) systems.

\section{Author Information}


Corresponding Author

*E-mail: b.falzon@qub.ac.uk( Brian.G.Falzon)

\section{Notes}

The authors declare no competing financial interest.

\section{Acknowledgments}

This work was supported by the UK Engineering and Physical Sciences Research Council (EPRSC) grant EP/N007190/1.

\section{References}


[1] Roth W, Giurgiutiu V. Structural health monitoring of an adhesive disbond through electromechanical impedance spectroscopy. Int. J. Adhes. Adhes 2017; 73: 09-117

[2] Mactabi R, Rosca ID, Hoa SV. Monitoring the integrity of adhesive joints during fatigue loading using carbon nanotubes. Compos. Sci.and Technol 2013; 78:1-9

[3]Giurgiutiu V. Structural health monitoring (SHM) of aerospace composites. Polymer Composites in the Aerospace Industry (2015): 449-507.

[4] Palaniappan J,Wang H, Ogin SL, Thorne AM,Reed GT, Crocombe AD, Rech Y, Tjin SC et al. Changes in the Reflected Spectra of Embedded Chirped Fibre Bragg Gratings Used to Monitor Disbonding in Bonded Composite Joints. Compos. Sci. and Technol 2007;67: 28472853.

[5]Murayama H, Kageyama K, Uzawa K, Ohara K, Igawa H. Strain monitoring of a singlelap joint with embedded fiber-optic distributed sensors. Struct. Health Monit (2011); 11:325344.

[6] Habib F, Martinez M, Artemev A, Brothers M.Structural Health Monitoring of Bonded Composite Repairs: A Critical Comparison between Ultrasonic Lamb Wave Approach and Surface Mounted Crack Sensor Approach. Compos. Part B-Eng 2013; 47:26-34.

[7] Zhang H, Bilotti E, Peijs T.The use of carbon nanotubes for damage sensing and structural health monitoring in laminated composites: a review. Nanocomposites 2015; 4: $167-184$

[8]Gao L, Thostenson ET, Zhang Z, Chou TW, Coupled carbon nanotube network and acoustic emission monitoring for sensing of damage development in composites. Carbon 2009; 47:381-1388.

[9] Chou TW,Gao L,Thostenson ET. An assessment of the science and technology of carbon nanotube-based fibers and composites. Compos. Sci. Technol 2010; 70:1-19.

[10] Thostenson ET, Chou TW. Carbon Nanotube Networks: Sensing of Distributed Strain and Damage for Life Prediction and Self-Healing. Adv. Mater 2006; 18:2837-2841.

[11]Gao LM, Thostenson ET, Zhang ZG, Chou TW. Sensing of damage mechanisms in fiberreinforced composites under cyclic loading using carbon nanotubes. Adv. Funct. Mater 2009; 19:23-130.

[12] Liu H, Y Li, Dai K,Zheng G,Liu C, Shen C,Yan X, Guo J, Guo Z. Electrically conductive thermoplastic elastomer nanocomposites at ultralow graphene loading levels for strain sensor applications. J. Mater. Chem. C 2016; 4:157-166.

[13]Park M,Kim H,Youngblood JP. Strain-dependent electrical resistance of multiwalled carbon nanotube/polymer composite films. Nanotechnol 2008;19: 055705. 
[14]Duan L, Fu S,Deng H, Zhang Q, Wang K, Chen F, Fu Q. The resistivity-strain behavior of conductive polymer composites: stability and sensitivity. J. Mater. Chem. A 2014; 2:17085.

[15]Wang N, Xu Z, Zhan P, Dai K, Zheng G, C. Liua C,Shena CA. Tunable strain sensor based on a carbon nanotubes/electrospun polyamide 6 conductive nano-fibrous network embedded into poly(vinyl alcohol) with self-diagnosis capabilities. J. Mater. Chem. C 2017;5:4408.

[16]Lee J, Lim M, Yoon J, Kim MS, Choi B, Kim DM, Kim DH, Park I, Choi SJ et al.Transparent, flexible strain sensor based on a solution-processed carbon nanotube network. ACS Appl. Mater. Interfaces 2017; 9:26279-26285.

[17] Kwon DJ, Wang ZJ, Choi JY, Shin PS, DeVries KL, Park JM. Damage sensing and fracture detection of CNT paste using electrical resistance measurements. Compos. Part BEng 2016; 90:386-391.

[18]Kang M.H, Choi JH, Kweon JH. Fatigue life evaluation of and crack detection of the adhesive joint with carbon nanotubes. Compos. Struct 2014; 108:417-422.

[19] Lim AS,Melrose ZR,Thostenson ET, Chou TW. Damage sensing of adhesively-bonded hybrid composite/steel joints using carbon nanotubes.Compos. Sci. and Technol. 2011;71 1183-1189.

[20] Garcia C, Sanchez M, Urena A, Rams J. Carbon Nanotubes for Assessing the Structural Integrity of Composite Bonded Joints with Film Adhesives. In Structural Health Monitoring: System Reliability for Verification and Implementation 2015; 2: 2169-2176.

[21]Sanchez-Romate XF,Molinero J, Jimenez-Suarez A, Sanchez M, Guemes A,Urena A. Carbon Nanotube-Doped Adhesive Films for Detecting Crack Propagation on Bonded Joints: A Deeper Understanding of Anomalous Behaviors. ACS Appl. Mater. Interfaces 2017; 9:43267-43274.

[22] Robert C, Feller JF, Castro M.Sensing Skin for Strain Monitoring Made of PC-CNT Conductive Polymer Nanocomposite Sprayed Layer by Layer. ACS Appl. Mater.Interfaces 2012; 4:3508-3516.

[23]Wang X, Sparkman J, Gou J. Strain sensing of printed carbon nanotube sensors on polyurethane substrate with spray deposition modelling. Compos. Commun 2017; 3:1-6.

[24]Amjadi M, Yoon YJ,Park I. Ultra-stretchable and skin-mountable strain sensors using carbon nanotubes-Ecoflex nanocomposites.Nanotechnol 2015;26:375501. 
[25] Yao X, Falzon BG, Hawkins SC, Tsantzalis S. Aligned carbon nanotube webs embedded in a composite laminate: Aroute towards a highly tunable electro-thermal system. Carbon 2018; 129:486-494.

[26] Huynh CP, Hawkins SC.Understanding the synthesis of directly spinnable carbon nanotube forests. Carbon 2010; 48:1105-1115.

[27] Mathur A, Tweedie M, Roy SS, Maguire PD, McLaughlin JA. Electrical and Raman spectroscopic studies of vertically aligned multi-walled carbon nanotubes. J Nanosci Nanotechnol 2009; 9:4392-6.

[28] Zhang B , Xu Y, Zheng Y, Dai L, Zhang M, Yang J, Chen Y, Chen X, Zhou J.A Facile Synthesis of Polypyrrole/Carbon Nanotube Composites with Ultrathin, Uniform and Thickness-Tunable Polypyrrole Shells. Nanoscale Research Letters 2011; 6:431.

[29] Wang Y, Li M, Gu Y, Zhang X, Wang S, Li Q. Zhang Z. Tuning carbon nanotube assembly for flexible, strong and conductive films. Nanoscale 2015; 7: 3060

[30] Dume L, Sears K, Mudie S, Kirby N, Skourtis C, Mcdonnell J, Lucas S, Schutz J, Finn N, Huynh C, Hawkins S, Kong L, Hodgson P, Duke M, Gray S. Characterization of carbon nanotube webs and yarns with small angle X-ray scattering: Revealing the yarn twist and inter-nanotube interactions and alignment. Carbon 2013; 63:562-592.

[31] Atkinson KR, Hawkins SC, Huynh C, Skourtis C, Dai J, Zhang M, Fang S, Zakhidov AA, Lee SB, Aliev AE, Williams CD, Baughman RH. Multifunctional carbon nanotube yarns and transparent sheets: Fabrication, properties, and applications. Physica B 2007; 394: 339_ 343.

[32] Miao M , McDonnell J, Vuckovic L, Hawkins SC. Poisson's ratio and porosity of carbon nanotube dry-spun yarns. Carbon 2010; 48:2802-2811.

[33] Bodjona K, Lessard L. Hybrid bonded-fastened joints and their application in composite structures: A general review. Journal of Reinforced Plastics and Composites 2016; 35(9):764-781.

[34]Sengezer EC, Seidel GD, Bodnar RJ, Anisotropic piezoresistivity characteristics of aligned carbon nanotube-polymer nanocomposites. Smart Mater.Struct 2017;26: 095027.

[35]Vadlamani VK, Chalivendra VB, Shukla A, Yang S, Sensing of damage in carbon nanotubes and carbon black-embedded epoxy under tensile loading. Polym. Compos 2012; 33:809-15.

[36]R. Moriche, M. Sanchez, A. Jimenez-Suarez, S.G. Prolongo, A. Urena, Strain monitoring mechanisms of sensors based on the addition of graphene nanoplatelets into an epoxy matrix. Compos. Sci. Technol.123 (2016)65-70. 
[37]Cao X, Wei X, Li G, Hu C, Dai K, Guo J, Zheng G, Liu C, Shen C, Guo Z. Strain sensing behaviors of epoxy nanocomposites with carbon,nanotubes under cyclic deformation.Polym 2017;112:112,1-9.

[38] Aly K, Li A, Bradford PD. Strain sensing in composites using aligned carbon nanotube sheets embedded in the interlaminar region. Compos Part A Appl Sci Manuf 2016; 90:536548.

[39] Li M, Wang J, Wang S, Zuo T, Sun W, Gu Y, Zhang Z. Effect of microstructure on the piezoresistive behavior of carbon nanotube composite film. Mater. Res. Express 2019; 6: 025034

[40] Ma L, Yang W, Wang Y, Chen H, Xing Y, Wang J. Multi-dimensional strain sensor based on carbon nanotube film with aligned conductive networks. Composites Science and Technology 2018; 165:190-197.

Yamada T, Hayamizu Y, Yamamoto Y, Yomogida Y, Najafabadi AI, Futaba DN, Kenji [41] Hata K. A stretchable carbon nanotube strain sensor for human-motion detection. Nat. Nanotechnol 2011; 6:296-301.

[42] Yu Y, Luo S,Sun Li, Wu Y,Jiang K, Li Q, Wang J, Fan S. Ultra-stretchable conductors based on buckled super-aligned carbon nanotube films. Nanoscale 2015; 7: 10178-10185

[43] Wang X, Li J, Song H, Huang H, Jihua Gou.Highly Stretchable and Wearable Strain Sensor Based on Printable Carbon Nanotube Layers/Polydimethylsiloxane Composites with Adjustable Sensitivity. ACS Appl. Mater. Interfaces 2018; 10: 7371-7380.

[44]Amjadi M, Kyung KU, Park I, Sitti, M. Stretchable, Skin-Mountable, and Wearable Strain Sensors and Their Potential Applications: A Review. Adv. Funct. Mater 2016; 26:1678-1698.

[45]Yu Y, Luo Y, Guo A, Yan L, Wu Y, Jiang K, Li Q, Fan S, Wang J. Flexible and transparent strain sensors based on super-aligned carbon nanotube films. Nanoscale 2017; 9:6716.

[46]Li A, Bogdanovich AE, Bradford PD. Aligned carbon nanotube sheet piezoresistive strain sensors. Smart Mater.Struct 2015; 24:095004

[47]Tung TT, Karunagaran R, Tran NH, Gao B, Chowdhury SN, Pillin I, Castro M, Feller JF, Losi D, Engineering of graphene/epoxy nanocomposites with improved distribution of graphene nanosheets for advanced piezo-resistive mechanical sensing. J. Mater. Chem. C 2016; 4:3422-3430. 
[48]. Ma L, Yang W, Wang Y, Chen H, Xing Y, Wang J. Multi-dimensional strain sensor based on carbon nanotube film with aligned conductive networks. Composites Science and Technology 2018; 165:190-197.

[49]. Ku-Herrera JJ, Pacheco-Salazar OF, Ríos-Soberanis CR, Domínguez-Rodríguez G, Avilés F. Self-Sensing of damage progression in unidirectional multiscale hierarchical composites subjected to cyclic tensile loading. Sensors 2016: 16(3): 400

\section{Graphical abstract}

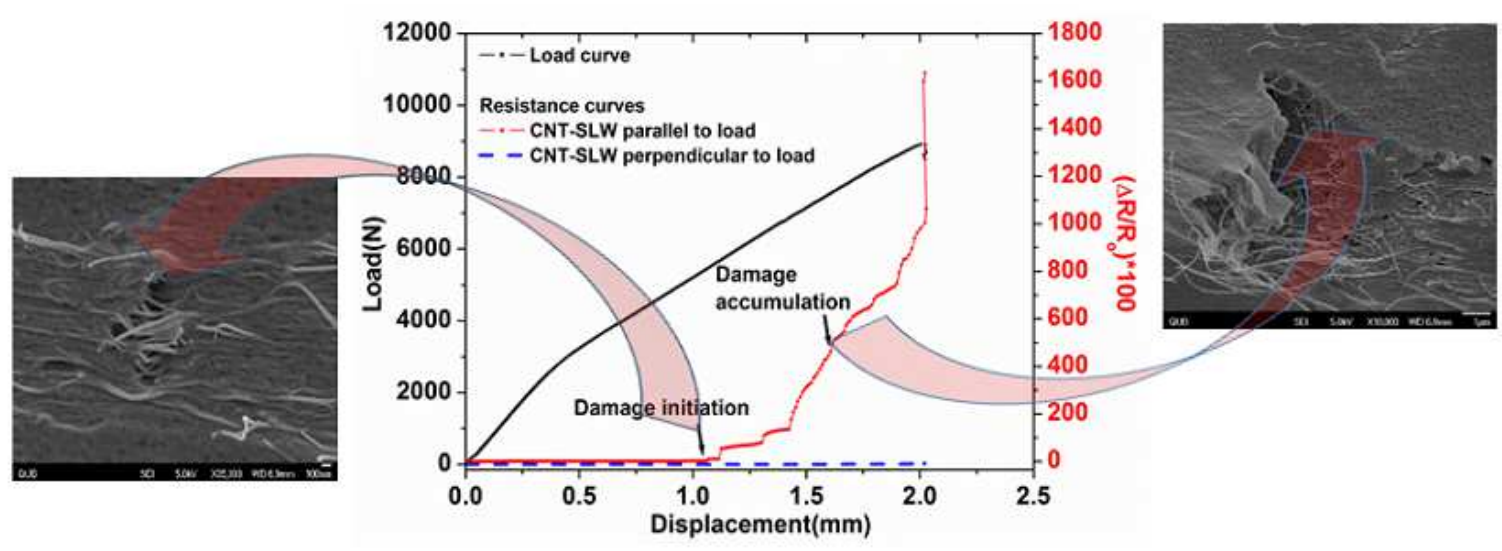

